\title{
ipen
}

AUTARQUIA ASSOCIADA À UNIVERSIDADE DE SÃO PAULO

\section{EFEITOS DA RADIAÇÃO LASER EM BAIXA INTENSIDADE NA CICATRIZAÇÃO DE QUEIMADURAS DE PELE. ESTUDO LASER DOPPLER FLUXOMÉTRICO E HISTOLÓGICO EM RATOS}

STELLA THYEMI SUGAYAMA

Dissertação apresentada como parte dos requisitos para obtenção do Grau de Mestre em Ciências na Área de Tecnologia Nuclear - Materiais.

Orientadora:

Profa. Dra. Martha Simões Ribeiro

São Paulo 2006 


\section{INSTITUTO DE PESQUISAS ENERGÉTICAS E NUCLEARES}

AUTARQUIA ASSOCIADA À UNIVERSIDADE DE SÃO PAULO

\section{EFEITOS DA RADIAÇÃO LASER EM BAIXA INTENSIDADE NA CICATRIZAÇÃO DE QUEIMADURAS DE PELE. ESTUDO LASER DOPPLER FLUXOMÉTRICO E HISTOLÓGICO EM RATOS}

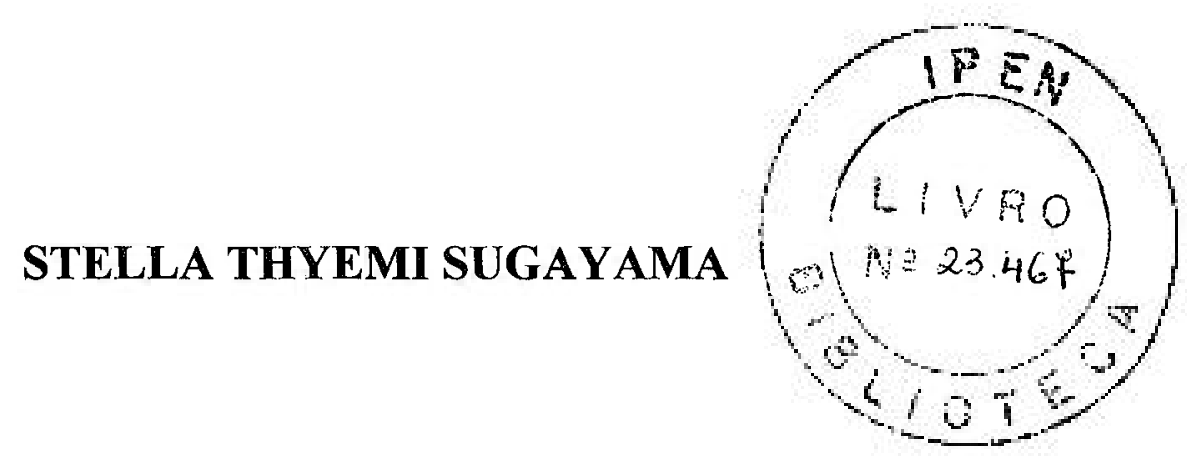

Dissertação apresentada como parte dos requisitos para obtenção do grau de Mestre em Ciências na Área de Tecnologia Nuclear-Materiais

Orientadora:

Profa. Dra. Martha Simões Ribeiro 


\section{AGRADECIMENTOS}

Aos meus pais, Júlia e Yoshikatsu, muito obrigada por sempre estarem ao meu lado, direcionando-me nas decisões, incentivando-me nos momentos mais difíceis e confiando na minha capacidade como pessoa. Vocês são as pessoas mais importantes para mim, se pude estudar, trabalhar e me desenvolver como pessoa foi graças̉ aos esforços e dedicação de vocês.

À minha irmã Camilla, agradeço pelas conversas que confortaram meu coração, pela amizade e apoio durante todos estes anos.

Ao meu irmão Rafael, por estar ao lado dos meus pais enquanto estamos longe.

Aos meus avós (in memoriam), que desde criança sempre nos incentivaram a estudar e nos proporcionaram condições para ter todo conhecimento necessário. 
Caminho de mil milhas começa com o primeiro passo

"Sonhem, ainda que o sonho pareça impossível, Lutem, ainda que o inimigo pareça invencível, Suporte a dor, ainda que esta seja insuportável, Corra por onde o corajoso não ousa ir, Transforme o mal em bem, ainda que seja necessário caminhar mil milhas, Amem o puro e o inocente, ainda que seja inexistente Resistam ainda que o corpo não resista mais, E ao final, alcançarão aquela estrela, ainda que pareça inalcançável” 


\section{AGRADECIMENTOS}

À Profa. Dra. Martha Simões Ribeiro, minha orientadora, por ter me recebido como aluna, pela oportunidade em realizar este mestrado. Sua orientação, conhecimento, amizade, paciência e confiança me proporcionaram, nestes anos, aprendizado que perdurarão por toda vida.

Ao Prof. Dr. Gessé Eduardo Calvo Nogueira, que colaborou com este trabalho, transmitindo seus conhecimentos sobre o tema estudado, sempre com paciência e dedicação.

À Profa. Dra. Cristiane França, por ter aceitado ser colaboradora deste trabalho, pelo muito que aprendi de histopatologia, pelo carinho e amizade nos momentos de grande importância.

À Profa. Dra. Nancy Nascimento, responsável pelo Biotério do IPEN, por sempre colaborar com nossos trabalhos, pela sua dedicação e carinho com os animais que utilizamos para os experimentos.

À Prófa. Dra. Sônia Lícia Baldochi, por ter colaborado com este trabalho na parte de microscopia óptica, onde pudemos enriquecer nossa pesquisa.

À Profa. Dra. Denise Maria Zezell, pelo convívio e amizade nestes anos de estudo. 
À Neide, que se responsabiliza e cuida tão bem do biotério do IPEN, pela sua amizade, dedicação e grande apoio neste trabalho. Uma das maiores experiências de vida foi ter feito com você os experimentos com os ratinhos.

Ao Valdir, pelo apoio em todos os momentos, sempre muito solícito e disposto a ajudar.

Ao Ipen e seus funcionários, que de alguma forma sempre estiveram me ajudando durante estes anos de estudo.

Ao Dr. Daisaku Ikeda, grande humanista, propagador da paz, cultura e educação, foram seus incentivos e orientações que despertaram meu interesse em adquirir mais conhecimentos e ter sonhos grandiosos.

Aos meus amigos da organização Soka Gakkai, que contribuem para meu crescimento pessoal, pela amizade e apoio.

Ao Dr. Jorge Higashino e esposa Lúcia, que muito me ajudaram como uma família, pelo apoio e compreensão.

Aos meus amigos Úrsula Bezerra, João Páschoa, Rodrigo Salles, Marco Antônio Farroni, Ana Paula Aiello, Fernanda e Flávio Elorsa, Juliana Dalla Pria, Maria Isabel Matias, pela amizade, carinho, apoio e incentivo, amigos de todas as horas que jamais me deixaram desistir dos meus objetivos, cada um me ajudou de alguma forma muito especial a realizar este mestrado e fazem parte da minha vida com muito orgulho. 
Ao Prof. Dr. Nilson Dias Vieira Jr., gerente do Centro de Lasers e Aplicações, pelo conhecimento.

Aos demais Professores e colegas do Centro de Lasers e Aplicações, pelo conhecimento que pude adquirir neste mestrado.

À Karin Müller, por ter me apresentado à Profa. Dra. Martha Simões Ribeiro e ao IPEN, pela amizade e apoio.

À Silvia Núñez, grande colega de grupo, pelos seus conhecimentos, apoio, amizade e paciência. Sem sua ajuda e incentivo teria sido tudo mais difícil.

À Daniela Teixeira, grande colega de grupo, pelo incentivo nas horas mais difíceis, pelo seu carinho e apoio com os ratinhos do experimento. Aprendi muito com seu jeito amigo e sincero de ser.

À Claudia Emílio, pela amizade sincera, carinho e apoio em todos os momentos, pelas risadas e conversas que tivemos; ter conhecido uma pessoa como você foi muito importante.

Ao Renato Prates e Aguinaldo Garcez, pela amizade, simplicidade e disponibilidade em ajudar e dividir seus conhecimentos.

À Renata, Patrícia e ao Tiago pela amizade e apoio nestes anos de convívio no laboratório. 


\section{EFEITOS DA RADIAÇÃO LASER EM BAIXA INTENSIDADE NA CICATRIZAÇÃO DE QUEIMADURAS DE PELE. ESTUDO LASER DOPPLER FLUXOMÉTRICO E HISTOLÓGICO EM RATOS}

\section{Stella Thyemi Sugayama}

Queimaduras severas causam trauma às vítimas, pela perda de líquido corpóreo, injúria no sistema vascular cutâneo e demora na cicatrização das lesões. A irradiação com laser em baixa intensidade vem sendo estudada como tratamento alternativo, por ser uma terapia não-invasiva e capaz de acelerar o processo de cicatrização. $O$ objetivo deste estudo foi avaliar os efeitos do laser de baixa potência $(\lambda=660 \mathrm{~nm})$ em queimaduras de pele por histomorfometria e fluxometria laser Doppler utilizando duas condições de irradiação. Trinta e seis animais com duas queimaduras criadas por vapor foram divididos em três grupos: no grupo dose fracionada (GF), as lesões foram irradiadas com dose de $1 \mathrm{~J} / \mathrm{cm}^{2}$ nos dias 1, 3, 8 e 10; no grupo dose única (GU), as lesões foram irradiadas com dose de $4 \mathrm{~J} / \mathrm{cm}^{2}$ no dia 1. O grupo controle (GC) não foi irradiado. O fluxo sanguíneo foi monitorado nos dias $3,8,10,15$ e 21 e três animais por grupo foram sacrificados nestes momentos. Os grupos irradiados mostraram um pico de vasos neoformados no dia 15 , enquanto que o pico do GC foi no dia 21. O número de vasos no GC foi significantemente maior que GF e GU no dia 21. Com relação ao fluxo sangüíneo, os grupos irradiados mostraram um valor mais alto que o controle no dia 8 , porém, sem diferenças significantes entre os grupos. Estes achados sugerem que o laser acelera a cicatrização de queimaduras, porém, sem diferenças significativas entre as doses estudadas. 


\section{EFFECTS OF LOW INTENSITY LASER RADIATION ON BURNED \\ SKIN HEALING. A LASER DOPPLER FLOWMETRY \\ AND HISTOLOGICAL STUDY IN RATS}

\section{Stella Thyemi Sugayama}

Severe burn injuries cause extensive damage and are notoriously complicated by loss of body fluids, injury in the cutaneous vasculature and delayed wound healing. Low intensity laser therapy (LILT) has been studied as an alternative method since it is a non invasive treatment and is able to accelerate wound healing. The purpose of the present study was to evaluate the effects of LILT $(\lambda=660 \mathrm{~nm})$ in burned skin with two different doses by histomorphometry and laser Doppler flowmetry. Thirdy six male adult Wistar rats with two burns created on the back using water vapor were divided into 3 groups. In the fractioned dose laser group (GF), the lesions were irradiated with $1 \mathrm{~J} / \mathrm{cm}^{2}$ on days $1,3,8$ and 10; in the single dose laser group (GU), the lesions were irradiated with $4 \mathrm{~J} / \mathrm{cm}^{2}$ on day 1. On control group (GC) lesions were not irradiated. The blood flow was measured on days $1,3,8,10,15$ and 21 and three animals per group were sacrificed in these moments. Irradiated groups showed a peak of new blood vessels formation on day 15 while for GC the peak was on day 21. At this moment, the number of vessels in GC was significantly higher than GF and GS. Regarding to blood flux, irradiated groups displayed a higher value than GC on day 8 , though no significant differences were observed. These findings suggest that LILT may accelerate skin repair, however, no significant differences were observed between the studied doses. 


\section{SUMÁRIO}

Pagina

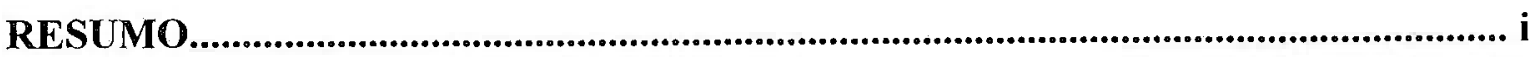

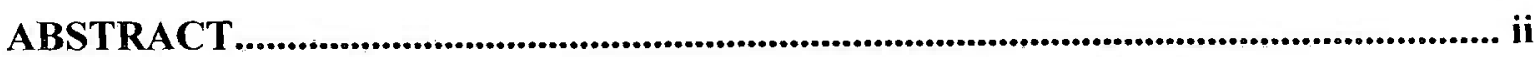

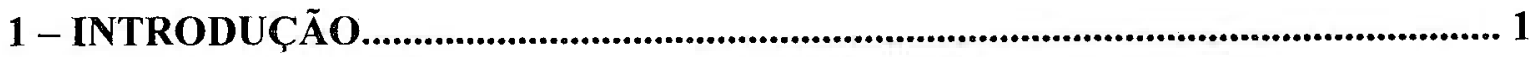

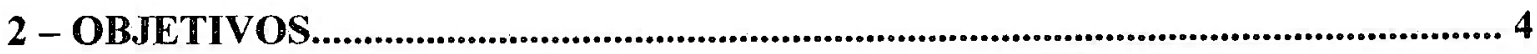

3 - REVISÃO DA LITERATURA

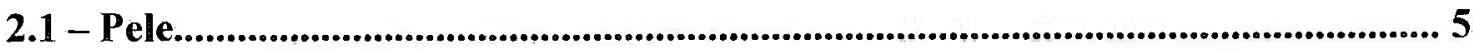

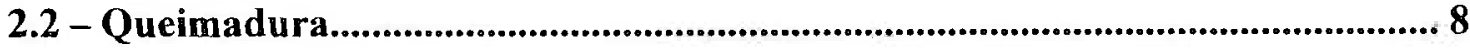

2.3 - Cicatrização de lesões de queimadura......................................................... 11

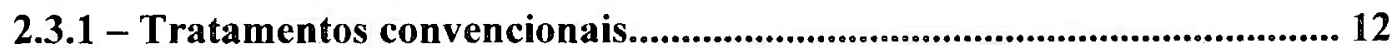

2.3.2 - Laser em baixa intensidade.......................................................... 14

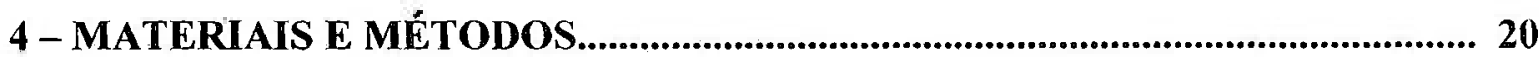

5 - RESULTADOS

5.1-Análise fluxometria laser Doppler................................................................. 28

5.2 - Análise histológica........................................................................................... 31

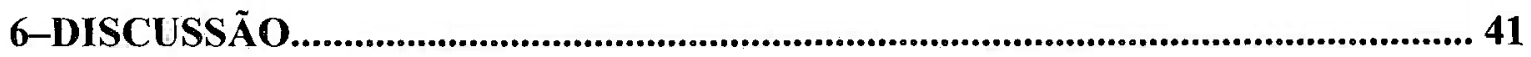


CONCLUSÃO

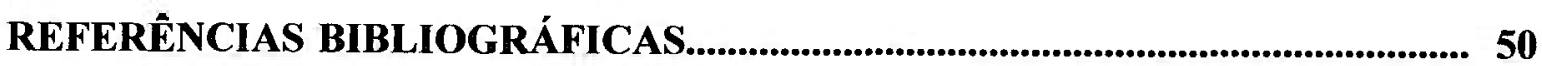




\section{SUMÁRIO}

Pagina

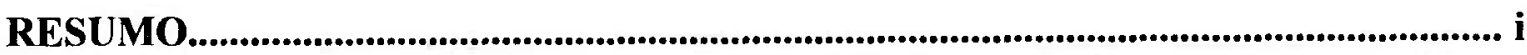

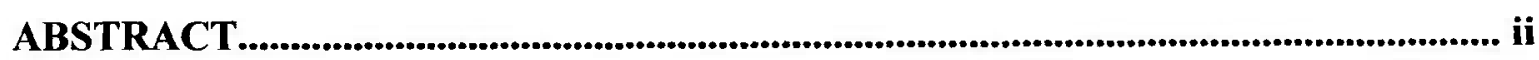

1 - INTRODUÇÃ

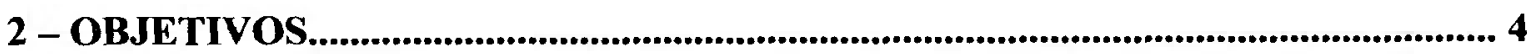

3 - REVISÃO DA LITERATURA

2.1 - Pele

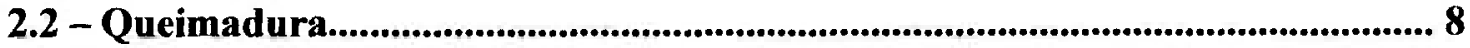

2.3 - Cicatrização de lesões de queimadura................................................................ 11

2.3.1 - Tratamentos convencionais....................................................... 12

2.3.2 - Laser em baixa intensidade........................................................... 14

4-MATERIAIS E MÉTODOS............................................................................ 20

5 - RESULTADOS

5.1-Análise fluxometria laser Doppler...................................................................... 28

5.2 - Análise histológica.............................................................................................. 31 


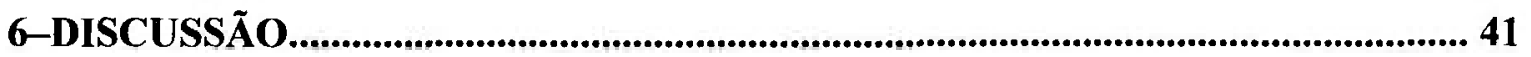

CONCLUSĀ̇

REFERÊNCIAS BIBLIOGRÁFICAS................................................................. 50 


\section{1- INTRODUÇÃo}

A integridade dos tecidos é essencial para o correto funcionamento dos sistemas biológicos. Alterações morfológicas podem ser provocadas por danos físicos, químicos e microbiológicos. As queimaduras, por exemplo, causam alterações morfológicas associadas a trauma.

Para o tratamento de queimaduras é necessário compreender a fisiopatologia da área afetada, sendo de fundamental importância a extensão e a profundidade da ferida. A gravidade das lesões cutâneas provocadas pelo dano térmico é diretamente proporcional à intensidade e duração da exposição à fonte, sendo dividida em lesões de primeiro, segundo e terceiro graus. As queimaduras de terceiro grau têm sido grande foco de pesquisas em busca de tratamentos mais conservadores e de maior rapidez no reparo para um resultado funcional e estético satisfatório ${ }^{1}$.

A terapêutica convencional consiste no uso de medicamentos tópicos como antimicrobianos a base de prata e para lesões mais profundas e extensas, enxertos de pele natural ou substituto de pele (pele sintética, cobertura medicamentosa ou pele animal) ${ }^{2}$.

A terapia laser em baixa intensidade vem se destacando como uma das ações terapêuticas possíveis para auxiliar o processo de reparação de feridas cutâneas. A biomodulação, ou o uso de lasers sem efeito térmico em aplicações clínicas, foi relatado pela primeira vez pelo professor Endre Mester e equipe, que demonstraram os efeitos da radiação sobre a pele lesionada de ratos ${ }^{3}$. 
Desde então, trabalhos são encontrados na literatura relatando os efeitos do laser em baixa intensidade na estimulação da atividade celular incluindo o aumento na síntese de ATP, aumento do potencial da membrana mitocondrial, diferenciação de fibroblastos em miofibroblastos e proliferação de queratinócitos ${ }^{4,5}$. Em experimentos com animais, tem sido observada a estimulação do processo de cicatrização incluindo a proliferação de fibroblastos, aumento da reepitelização, síntese de colágeno e formação de tecido de granulação, efeitos locais no sistema imunológico e aumento na formação de vasos capilares $^{4,5}$.

O mecanismo de ação do laser na cicatrização não é completamente conhecido, muitas são as possíveis explicações para os efeitos clínicos observados. Fatores como comprimento de onda da radiação utilizada para a terapia, regime de operação do laser (contínuo ou pulsado), intensidade, densidade de energia ou fluência, tempo de irradiação, intervalos de tratamento e o método de irradiação são aspectos a serem considerados, pois podem alterar a possibilidade de se obter os efeitos biológicos desejados ${ }^{6}$.

A função microcirculatória desempenha importante papel no processo de reparação tecidual, permitindo a chegada de células de defesa na área afetada. A modulação do fluxo sanguíneo encontra-se como um dos efeitos associados à terapia laser em baixa intensidade, sendo este dado associado a resultados benéficos na reparação tecidual bem como na obtenção do efeito analgésico. Segundo Danhof, os efeitos do laser na microcirculação sangüínea podem ser gerados por uma ação indireta sobre os esfíncteres pré-capilares através da liberação de substâncias químicas como a histamina e a serotonina. Sob condições patológicas, o laser pode atuar sobre a microcirculação sanguínea promovendo um aumento da atividade celular gerando aumento da circulação, 
tendo como conseqüência a vasodilatação de arteríolas ${ }^{7}$.

Entretanto, trabalho recente de Núñez et al. mostrou que a irradiação de queimaduras com laser de He-Ne com densidade de energia de aproximadamente $1 \mathrm{~J} / \mathrm{cm}^{2}$, feita em três aplicações consecutivas com espaçamento de 24 h entre elas, apresentou um aumento percentual de fluxo sanguíneo no sétimo dia do processo de reparação em relação aos espécimes não-irradiados, porém, sem diferença estatística significante entre os grupos $^{8}$

É bem conhecido que a dose do tratamento, ou densidade de energia, é um dos parâmetros mais importantes para observação dos efeitos positivos obtidos com esta terapia. A densidade de energia é uma grandeza física que avalia a possibilidade de estimulação, inibição ou não-manifestação dos efeitos terapêuticos. Contudo, apesar da vasta literatura, nota-se que as informações sobre a dose muitas vezes são conflitantes, já que alguns autores sugerem que a dose é acumulativa ${ }^{9,10}$; outros, que os efeitos são acumulativos 6 .

Deste modo, a proposta deste estudo é investigar os efeitos do laser em baixa intensidade no processo de cicatrização de queimaduras de terceiro grau, in vivo, comparando o tratamento entre dose fracionada, aplicada em momentos específicos do processo de cicatrização, e dose única, monitorando o fluxo sanguíneo e avaliando, por microscopia de luz, a morfologia do tecido em reparação. 


\section{2 - OBJETIVOS}

Avaliar os efeitos da terapia com laser em baixa intensidade no processo de cicatrização de queimaduras de terceiro grau, produzidas em pele de ratos, por histomorfometria e monitoramento do fluxo sanguíneo;

Comparar os efeitos do laser em baixa intensidade, utilizando dose fracionada, aplicada em momentos especificos do processo de reparo, com dose única por histomorfometria e monitoramento do fluxo sanguíneo. 


\section{3- REVISÃO DE LITERATURA}

\section{1 - Pele ${ }^{11}$}

É um órgão do sistema tegumentar que recobre a superfície do corpo e constituise de uma porção epitelial de origem ectodérmica, a epiderme, e uma porção conjuntiva de origem mesodérmica, a derme.

A epiderme é a camada mais externa formada por tecido epitelial, possui um revestimento de camadas de células sobrepostas, sendo que as células superficiais são achatadas e compõem uma camada córnea rica em queratina; a pele é classificada como tecido epitelial estratificado pavimentoso queratinizado. A epiderme apresenta espessura variada de acordo com a região do corpo e nela encontram-se grande número de terminações nervosas.

A derme é o tecido conjuntivo logo abaixo da epiderme, apresenta espessura variável de acordo com a região observada, é formada por tecido conjuntivo frouxo e tecido conjuntivo denso. Nesta camada da pele encontram-se grande quantidade de vasos sanguíneos e linfáticos, fibras nervosas e os anexos da pele: folículos pilosos, glândulas sebáceas e sudoríparas que derivam da epiderme (figura 3.1). 


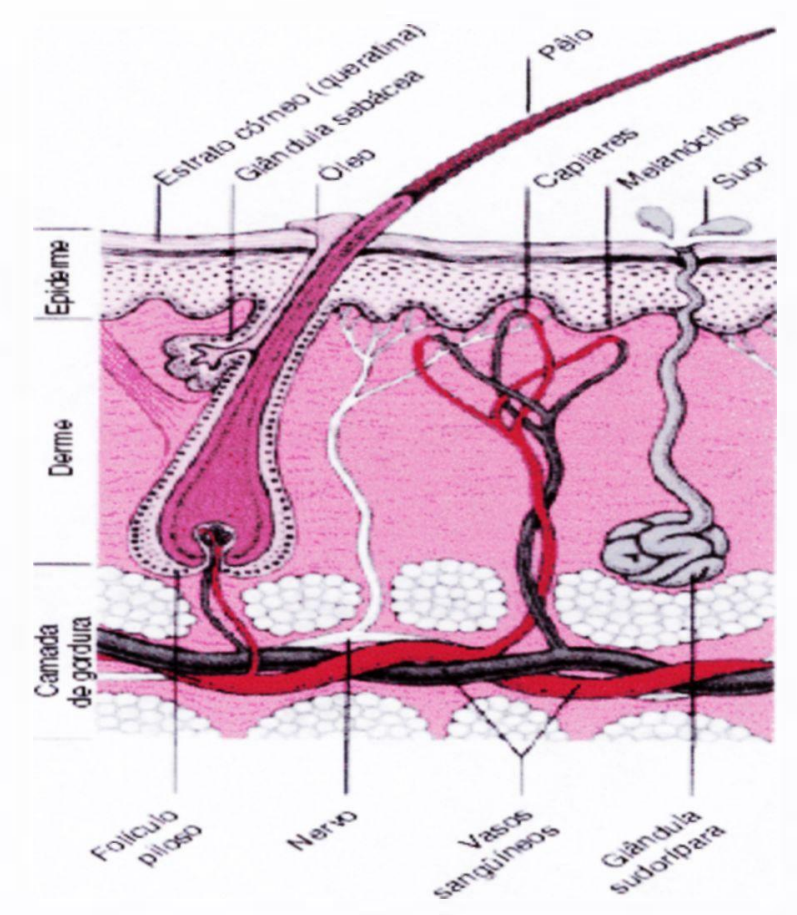

Figura 3.1 - Camadas da pele humana

Os capilares sangüíneos fazem parte do sistema circulatório localizado na derme, são vasos de pequeno calibre que ligam as extremidades das arteríolas às extremidades das vênulas. A parede dos capilares possui uma única camada de células (figura 3.2).

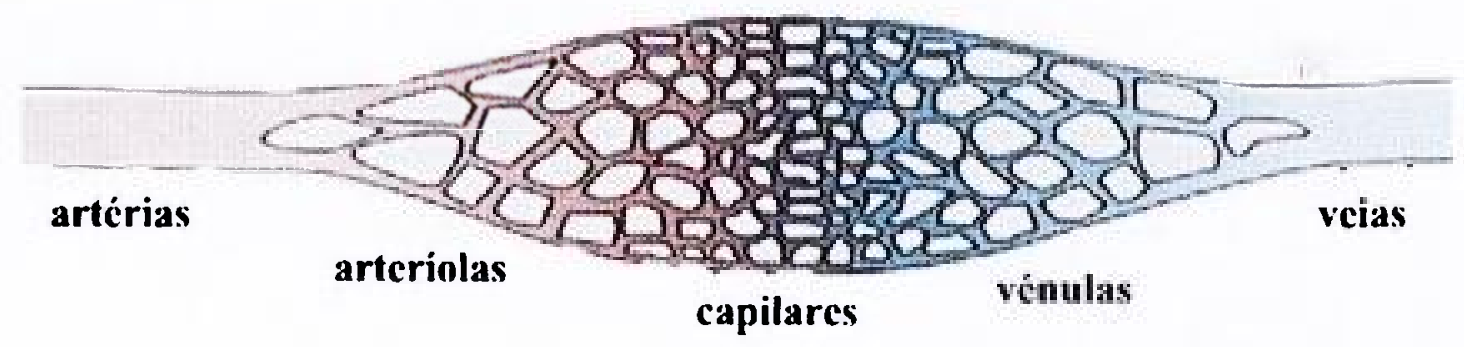

Figura 3.2: Esquema da rede vascular 
A pele é um sistema orgânico que participa do processo de manutenção do equilíbrio da temperatura corpórea, detecta os estímulos sensoriais e impede a entrada de substâncias no organismo sendo uma barreira protetora contra agentes externos.

A cor, a textura e as pregas da pele ajudam a caracterizar os indivíduos. Alterações na função ou no aspecto da pele podem acarretar conseqüências importantes para a saúde física e mental.

Para este estudo, realizamos queimadura de terceiro grau no dorso de rato que possui os mesmos elementos estruturais da pele humana, com exceção das glândulas sudoríparas. 


\section{2 - Queimaduras}

As queimaduras de pele podem ser provocadas pelo calor, frio, radiação, produtos químicos e eletricidade. Seu grau e gravidade variam de acordo com a intensidade do agente ou fonte, tempo de exposição e localização corpórea atingida.

Foram observadas acentuadas reduções tanto na taxa de mortalidade quanto no tempo de hospitalização a partir Do século XX. Este prognóstico mais favorável resulta de uma compreensão dos efeitos sistêmicos das queimaduras maciças e da descoberta de formas mais apropriadas para prevenir a infecção das feridas e facilitar a cicatrização da pele $^{2}$

Queimaduras severas causam extensos danos às vitimas pela quantidade de perda de fluidos corpóreos e pela susceptibilidade das áreas atingidas a infecções que podem levar à mortalidade. No século XIX, pacientes com até $10 \%$ de área corporal queimada apresentavam prognóstico desfavorável. Não era conhecida a necessidade de reposição de fluidos devido ao estado de desidratação gerado pela queimadura. Hoje, uma queimadura em $70 \%$ do corpo é grave, mas o prognóstico não é totalmente desfavorável, sendo dependente das condições hospitalares e dos recursos tecnológicos ${ }^{11,12}$.

A classificação das lesões em "grau" auxilia a identificação da profundidade e gravidade da queimadura. Mais recentemente, as queimaduras de primeiro e segundo grau têm sido denominadas queimaduras parciais da espessura da pele e queimaduras de terceiro grau, totais ou completas da espessura da pele ${ }^{12}$. 
De acordo com Robbins ${ }^{13}$, as queimaduras de primeiro grau apresentam clinicamente a epiderme eritematosa e edemaciada, e são extremamente dolorosas. Histologicamente apresentam ausência de adesão intercelular da epiderme (figura 3.2) ${ }^{13}$.

Nas queimaduras de segundo grau, clinicamente, a pele se apresenta eritematosa, com presença de bolhas, edema acentuado, e é extremamente dolorosa. Histologicamente apresenta vasodilatação acentuada na derme e necrose coagulativa (figura 3.3 ) ${ }^{13}$.

As queimaduras de terceiro grau ou de espessura total envolvem a necrose total da epiderme e da derme, com perda dos anexos dérmicos os quais fornecem células para a regeneração epitelial. Clinicamente, a pele se apresenta seca, de cor marmórea e rígida, a evolução é lenta, podendo levar meses para cicatrizar, produzindo severas marcas de cicatriz (figura 3.4$)^{13}$.

As manifestações locais mais importantes da queimadura, independente do seu grau ou extensão, são as formações de substâncias tóxicas e seu acúmulo, dor intensa, perda de líquido corporal, destruição dos tecidos e devido à perda da barreira protetora, podem ocorrer infecções na área.

De acordo com a Revista Brasileira de Saúde Ocupacional ${ }^{14}$, a extensão da queimadura de pele, ou seja, a área corporal atingida deve ser avaliada, sendo de fundamental importância para o diagnóstico e tratamento deste trauma. Uma das regras para avaliar a extensão das queimaduras é a regra dos 9. Outra é comparar a extensão da queimadura com a superfície da palma da mão do acidentado, que corresponde a aproximadamente $1 \%$ da superficie corporal. A classificação para avaliar a extensão das 
lesões é denominada baixa quando menos de $15 \%$ da superfície corporal é atingida, média entre 15 e $40 \%$ e alta mais de $40 \%$ do corpo atingido.

Segundo Fontana, a queimadura pode alterar a integridade de uma pessoa, causando desequilíbrio não apenas biológicos como também psicológicos e sociais ${ }^{15}$.

Neste trabalho, foram produzidas queimaduras de terceiro grau no dorso de ratos por vapor, adequando à metodologia proposta por Bayat e colaboradores ${ }^{16}$.

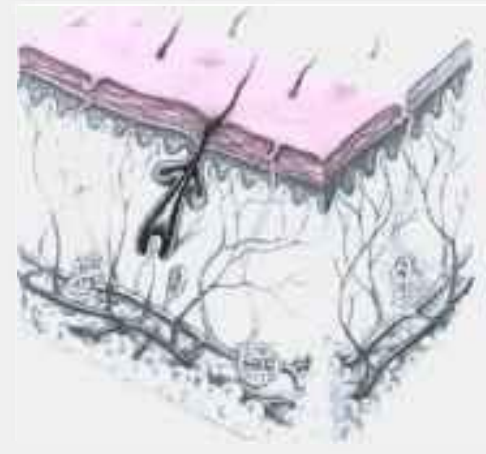

Figura 3.2:

Queimadura de

$1^{\circ} \operatorname{grau}^{17}$

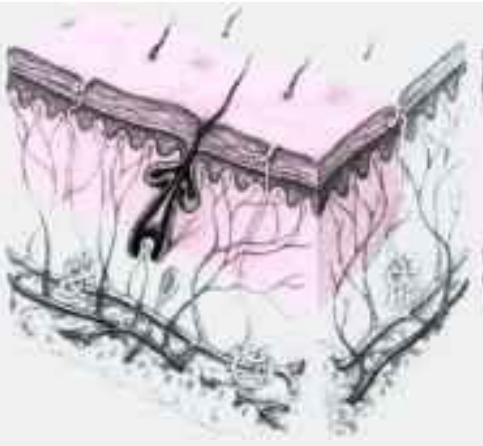

Figura 3.3:

Queimadura de

$2^{\circ} \operatorname{grau}^{17}$

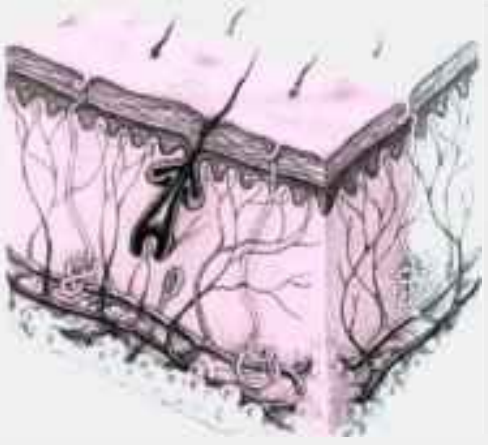

Figura 3.4:

Queimadura de

$3^{\circ} \operatorname{grau}^{17}$ 


\section{3 - Cicatrização de lesões de queimadura}

As lesões de queimadura cicatrizam por segunda intenção, onde os bordos da ferida se apresentam afastados em conseqüência da perda de parte dos tecidos. Inicialmente ocorre a fase inflamatória, seguido da fase proliferativa e por fim a fase de remodelamento do tecido ${ }^{13}$.

Em lesões com destruição da epiderme e parcial da derme, restam grandes mananciais de células epidérmicas que auxiliam na restauração do tecido. No entanto, queimaduras com destruição total da espessura da derme, como as de terceiro grau, o reparo inicia-se a partir da formação do tecido de granulação, sendo de extrema importância um tratamento que acelere o processo cicatricial, evitando contaminações do meio externo ${ }^{13,15}$.

A cicatrização de feridas provocadas por queimaduras se difere de acordo com o grau e a extensão da área atingida. Nas lesões de $1^{\circ}$ grau, geralmente a cicatrização ocorre em 3 a 4 dias, sem produção de cicatriz. Nas lesões de $2^{\circ}$ grau, ocorre em 14 a 21 dias, sem produção de cicatriz. No caso de queimadura de $3^{\circ}$ grau, a evolução é lenta, podendo levar meses para cicatrização completa, produzindo severas marcas de cicatriz.

As queimaduras de $3^{\circ}$ grau, por atingirem as camadas mais profundas da pele, são afetadas por complicações causadas pela injúria do sistema vascular cutâneo. A profundidade da lesão pode aumentar em 24 a $48 \mathrm{~h}$ devido ao progressivo fechamento vascular, produzindo uma zona de necrose coagulativa envolta por uma área de hiperemia. Inicialmente, a histamina liberada produz uma vasodilatação. Por sua vez, os leucócitos 
aderem às paredes dos vasos produzindo uma progressiva trombose, estendendo a área $\mathrm{e}$ aprofundando a lesão. A contínua ativação dos leucócitos provoca danos aos tecidos pela formação de radicais livres produzindo prolongada reação inflamatória que pode durar de 1 a 4 semanas $^{17}$.

As vítimas de queimaduras extensas de terceiro grau necessitam de internação hospitalar prolongada, aumentando assim, o risco de adquirir infecções nosocomiais. Inúmeros estudos vêm sendo desenvolvidos buscando novos métodos de diagnóstico e tratamento para melhorar o quadro clínico destes pacientes, procurando assim, diminuir mortalidade ${ }^{18}$

\subsection{1 - Tratamentos convencionais}

O reparo de uma extensa lesão de queimadura tem sido um grande problema, os estudos que abordam este tema têm como principais objetivos o desenvolvimento de tratamentos conservadores, de baixo custo visando promover um rápido reparo da área injuriada ${ }^{19}$.

Os tratamentos mais utilizados atualmente em extensas lesões de queimadura de terceiro grau são cirúrgicos. Os enxertos de pele natural ou sintética e coberturas com tampões medicamentosos a base de prata, sulfonamidas, cério e clorexidina têm sido os mais utilizados $2,12,17,18,20$. 
Por outro lado, mesmo sendo utilizado há décadas, medicamentos a base de prata vem sendo estudados quanto à sua toxicidade na proliferação celular. De acordo com alguns estudos, a exposição contínua a pequenas doses de íons prata, cobre, mercúrio e níquel podem provocar morte celular, impedir as divisões celulares ou ambas às situações $^{21}$.

Vincent et al., avaliaram em um estudo in vitro, a citotoxicidade de uma solução de nitrato de prata a $50-100 \mathrm{mg} / \mathrm{mL}(0,005-0,01 \%$ de prata) em cultura de queratinócitos e fibroblastos. Os resultados mostraram que a prata possui um efeito altamente tóxico às culturas de fibroblastos e queratinócitos, sendo os fibroblastos ainda mais sensíveis à exposição ao íon prata nas condições realizadas neste experimento ${ }^{21}$. Outros autores defendem o uso clínico controlado de tampões a base de prata, como comercialmente o Acticoat $^{\mathrm{TM} \otimes}$, pela facilidade de uso, por ser economicamente viável e quando comparado a outros antimicrobianos como acetato de clorexidine $0,5 \%$ e ácido fusidico $2 \%$ possui um efeito antimicrobiano mais eficaz ${ }^{20}$.

De acordo com Fontana, pesquisas mais recente têm como objetivo buscar novos recursos para melhorar o atendimento do paciente queimado. Nos Estados Unidos e Europa, o cultivo de epiderme em meios de cultura vem beneficiando muitas vítimas de queimadura através da criação de banco de pele ${ }^{15}$.

Por meio da biópsia da pele sadia de um doente queimado, a epiderme é separada da derme. Então, as células da epiderme também são separadas e semeadas em meio de cultura. Em algumas semanas as células se multiplicam formando uma lâmina de tecido transparente. Depois de crescidas, elas são aplicadas no indivíduo protegendo as lesões ${ }^{15}$. 
Outra alternativa é o enxerto de malha, utilizado quando existe mais área receptora que doadora. Uma lâmina de pele sadia é extraída e preparada através de um aparelho específico, fazendo com que a área desta lâmina passe a ter de duas a três vezes o seu tamanho original. Ao ser aplicada sobre a área receptora, a malha adere à região cobrindo a ferida ${ }^{15,18}$.

A utilização do laser em baixa intensidade, neste cenário, vem como uma terapia alternativa não-invasiva, podendo atuar como monoterapia ou coadjuvante aos tratamentos convencionais.

\subsection{2 - Laser em baixa intensidade}

O acrônimo LASER é composto pelas iniciais de Light Amplification by Stimulated Emission of Radiation, que significa amplificação da luz por emissão estimulada de radiação.

A vantagem da radiação laser, quando comparada a outros tipos de fontes de luz, é que se trata de um feixe monocromático, colimado e coerente. Parâmetros da irradiação como comprimento de onda, diâmetro de feixe, duração do pulso e tempo de exposição podem ser combinados com as propriedades físicas, químicas e biológicas do tecido alvo para que se obtenham resultados desejáveis. Quando a energia dos lasers é absorvida, podem ocorrer quatro tipos de interações teciduais: interação fotoquímica; interação fototérmica; interação fotomecânica; e interação fotoelétrica ${ }^{22}$. 
Os lasers em baixa intensidade vêm sendo utilizados nas áreas da saúde para promover estímulos sobre os processos moleculares e bioquímicos que ocorrem no processo de reparação tecidual. O uso desta terapia nas áreas biomédicas é um tópico relativamente recente. As pesquisas se iniciaram com os trabalhos de Mester et al., onde foi realizado um estudo em camundongos para análise do reparo em feridas cutâneas submetidas à irradiação com laser de rubi $(\lambda=694,3 \mathrm{~nm})$. Os resultados demonstraram aceleração na cicatrização das feridas, que sofreram contração tecidual equivalente a $50 \%$ no tempo de 7 dias, e decorridos 14 dias, as feridas demonstraram uma reparação diferenciada, fechando mais rapidamente que as do grupo controle não tratadas ${ }^{23}$.

Em outro estudo realizado pelo mesmo grupo, os autores observaram o reparo de feridas profundas, semelhantes à queimadura de terceiro grau no dorso de camundongos. Com objetivo de analisar os efeitos de diferentes doses na cicatrização de queimaduras cutâneas, os autores irradiaram as lesões com laser de nubi $(\lambda=694,3 \mathrm{~nm})$ nas doses de 0,5 ; $1 ; 4 ; 5$ e $10 \mathrm{~J} / \mathrm{cm}^{2}$. No fim do período experimental, aos 14 dias, observaram significativa aceleração do reparo tecidual, principalmente quando foi empregado $1 \mathrm{~J} / \mathrm{cm}^{2}$. Essa aceleração no reparo mostrava-se maior à medida que a área recebia nova irradiação laser $^{24}$.

Na década de 80, Haina et al avaliaram a formação de tecido de granulação cicatricial em feridas abertas provocadas na região dorsal de ratos, tratadas com laser de He-Ne $\left(50 \mathrm{~mW} / \mathrm{cm}^{2} ; \mathrm{D}=0,5 ; 1,5 ; 4 ; 10 ;\right.$ e $\left.20 \mathrm{~J} / \mathrm{cm}^{2}\right)$. Observaram maior formação de tecido de granulação com dose de $4 \mathrm{~J} / \mathrm{cm}^{2}$ e salientaram que acima dela os resultados não se mostraram significantes ${ }^{25}$. 
Bisht et al. provocaram feridas em ratos dos lados direito e esquerdo da coluna vertebral, com $8 \mathrm{~mm}$ de diâmetro. O lado direito serviu como controle e o esquerdo foi irradiado. Para a irradiação foi utilizado um laser de He-Ne. A densidade de energia utilizada foi de $4 \mathrm{~J} / \mathrm{cm}^{2}$, sendo realizado o tratamento durante 17 dias. $\mathrm{O}$ método de avaliação utilizado foi visual e histológico com biópsia realizada nos dias $3,5,7,9,12,15$ e 17 pós-operatório. Foram avaliadas a neovascularização, a proliferação de fibroblastos e a formação de colágeno. Em seus resultados, a terapia com laser em baixa intensidade promoveu um tempo de reparação menor. A diferença mais significante na quantidade de colágeno ocorreu no dia 9 , porém a maior produção ocorreu nos dias 3 e 4 , e a neovascularização teve maior significância nos dias 5 e 7 . De acordo com os resultados obtidos, os autores concluíram que a radiação emitida pelo laser de $\mathrm{He}-\mathrm{Ne}$ altera de forma positiva aumentando a proliferação de fibroblastos e acelera a epitelização, juntamente com a atividade de células fagocitárias e polimorfonucleares. Segundo estes estudos, os efeitos do laser de $\mathrm{He}-\mathrm{Ne}$ na reparação tecidual estão associados principalmente a reepitelização e a proliferação de fibroblastos nas áreas irradiadas ${ }^{26}$.

Muito embora a literatura apresente trabalhos que atestem à ação bioestimuladora do laser em baixa intensidade, outros, no entanto, não comprovaram ação benéfica do $\operatorname{laser}^{27,28}$. No trabalho de Cambier et al, foram criadas duas lesões em ambos os flancos de 20 ratos, divididos em dois grupos. O objetivo foi avaliar o efeito dos lasers de He-Ne e GaAlAs em cicatrização de queimaduras. No grupo 1, uma queimadura foi irradiada com laser de He-Ne na dose de $0,75 \mathrm{~J} / \mathrm{cm}^{2}$ e a segunda queimadura não foi irradiada, servindo como controle. No segundo grupo, uma das feridas foi exposta à irradiação com laser de GaAlAs, dose $0,21 \mathrm{~J} / \mathrm{cm}^{2}$, e a outra não recebeu tratamento. A irradiação foi feita uma vez por semana, durante 30 dias consecutivos. Nenhum efeito estimulante do laser foi 
observado para ambos os grupos no processo completo de cicatrização das queimaduras, 42 dias depois do início do experimento ${ }^{27}$.

Também, os efeitos do laser em baixa intensidade na cicatrização de queimaduras em ratos, comparando dois comprimentos de onda $(\lambda=635 \mathrm{~nm}$ e $\lambda=690 \mathrm{~nm})$, foram estudados por Schalenger et al. Trinta ratos foram queimados em ambos os flancos e aleatoriamente divididos em três grupos experimentais. No grupo A, ambas feridas permaneceram sem tratamento; nos grupos B e C, uma das feridas foi irradiada diariamente $\operatorname{com} \lambda=635 \mathrm{~nm}$ ou $\lambda=690 \mathrm{~nm}$, dose $1,5 \mathrm{~J} / \mathrm{cm}^{2}$, por trinta dias consecutivos, enquanto que a outra serviu como controle e não foi irradiada. Os critérios avaliados foram o diâmetro, eritema e edema das feridas. A análise diária demonstrou que os grupos foram similares em todo período de observação. Nas condições utilizadas nesse experimento, os comprimentos de onda $\lambda=635 \mathrm{~nm}$ e $\lambda=690 \mathrm{~nm}$, não produziram qualquer efeito benéfico no processo de cicatrização de queimaduras criadas em ratos ${ }^{28}$.

É bem conhecido que fatores como comprimento de onda da radiação utilizada para a terapia, regime de operação do laser (contínuo ou pulsado), densidade de energia, dose ou fluência, tempo de irradiação, intervalos de tratamento e o método de irradiação são aspectos a serem considerados, pois podem alterar a possibilidade de se obter os efeitos biológicos desejados. De acordo com Reddy, os efeitos estimulatórios do laser em reparo tecidual são relacionados a eventos específicos durante as primeiras duas fases da cicatrização de feridas, isto é, a fase inflamatória e a fase de proliferação, indicando que o período de intervenção pode ser crítico ${ }^{5}$.

No trabalho de Ribeiro et al, investigou-se o efeito do laser de He-Ne em baixa 
intensidade linearmente polarizado, aplicado em momentos específicos do reparo tissular, na cicatrização de queimaduras no dorso de ratos produzidas com nitrogênio líquido. Uma lesão foi deixada como controle sem irradiação, e nas outras duas lesões incidiu-se a luz com a polarização alinhada paralelamente à coluna vertebral do animal e com a polarização alinhada à direção perpendicular relativa. Os animais foram irradiados com 1 $\mathrm{J} / \mathrm{cm}^{2}$ nos dias $3,7,10$ e 14. A análise histológica indicou que o laser de He-Ne acelerou o reparo tecidual e, além disso, foi influenciado pele direção de polarização ${ }^{29}$.

Núñez et al., avaliaram os efeitos da irradiação com He-Ne na microcirculação sangüínea durante o processo de cicatrização de queimaduras em pele de ratos, usando a fluxometria laser Doppler. Foram realizadas três irradiações com intervalo de $24 \mathrm{~h}$ com densidade de energia de $1 \mathrm{~J} / \mathrm{cm}^{2}$. Em análise descritiva, foi observado aumento percentual de fluxo sanguíneo no sétimo dia do processo de reparação em relação aos espécimes nãoirradiados, porém, esse aumento não apresentou diferença estatística significante entre os grupos irradiados e controle não irradiado ${ }^{8}$.

Mais recentemente, os efeitos da cicatrização de queimaduras com laser em baixa intensidade foi também foco de estudos de Bayat e colaboradores. Sessenta ratos tiveram seu dorso queimado, com comprometimento da epiderme e derme. Foram divididos em 4 grupos: grupo controle sem tratamento, grupos laser tratado com $1,2 \mathrm{~J} / \mathrm{cm}^{2}$, grupo laser tratado com $2,4 \mathrm{~J} / \mathrm{cm}^{2}$ e grupo medicamento tópico a base de nitrofurazone 0,2\%. Os grupos foram tratados diariamente, desde o primeiro dia após a criação das queimaduras, até o fim do experimento. Os animais de cada grupo foram divididos em três subgrupos e sacrificados nos dias 7, 16 e 30 para análise histológica. Dez zonas de cada amostra foram analisadas em microscopia óptica para contagem de fibroblastos, 
macrófagos, neutrófilos e vasos sangüíneos. A profundidade da epiderme e derme neoformada foi medida em 10 pontos. Os resultados mostraram não haver diferença significante, em relação ao número de neutrófilos, fibroblastos, quantidade de vasos sangüíneos formados e profundidade de epiderme e derme neoformadas nas amostras analisadas nos dia 7,16 e 30 entre os grupos estudados ${ }^{16}$.

Apesar da vasta quantidade de trabalhos na literatura, nota-se que as informações sobre os efeitos da irradiação laser em baixa intensidade em tecidos biológicos são conflitantes e não conclusivas. Em trabalhos de lesões de queimadura com modelo animal, particularmente, existe ainda a dificuldade de se estabelecerem parâmetros adequados. Há muita divergência em relação à dose e momentos adequados para irradiação. Ainda, é bem conhecido que no processo de reparação cutânea pós-queimadura, a vascularização local encontra-se comprometida, retardando a cicatrização. 


\section{4- MATERIAIS E MÉTODOS}

O presente estudo foi realizado de acordo com os princípios éticos de experimentação animal elaborados pelo COBEA (Colégio Brasileiro de Experimentação Animal), entidade filiada ao International Council of Laboratory Animal Science (ICLAS), com base em normas internacionais, que visam o aprimoramento de condutas na experimentação animal baseando-se em três princípios básicos: sensibilidade, bom senso e boa ciência.

Foram utilizados 36 ratos (Rattus norvegicus albinos, Wistar), machos, adultos, com massa corpórea variando entre $350 \mathrm{~g}$ e $400 \mathrm{~g}$. Os animais foram mantidos no Biotério do IPEN em gaiolas individuais, em condições controladas de temperatura e em regime de luz de $12 \mathrm{~h} / 12 \mathrm{~h}$. Durante todo o experimento, receberam água e ração sólida ad libitum.

Todos os procedimentos experimentais foram realizados no mesmo período do dia para que as variações fisiológicas do metabolismo não interferissem nos resultados obtidos. Após a chegada na sala de procedimentos, os animais permaneceram em repouso por aproximadamente 10 minutos, para que ocorresse a climatização dos mesmos à temperatura do local.

Os animais foram anestesiados por via intramuscular com uma combinação anestésica de cloridrato de quetamina $(0,32 \mathrm{~mL} / \mathrm{Kg})$ e xilazina $(0,2 \mathrm{~mL} / \mathrm{Kg})$. Em seguida foi realizada a tricotomia da região dorsal e a pele desta área foi limpa com iodo povidine. Os animais foram mantidos no biotério por mais $24 \mathrm{~h}$, a fim de permitir-se um ajuste natural da microcirculação cutânea à perda de calor devido à remoção da camada de pelos 
desta região, bem como evitar uma possível resposta inflamatória provocada pelo uso da lâmina de tricotomia sobre a pele.

Antes do início do experimento, a superfície dorsal de cada animal foi medida com uma régua na linha da coluna vertebral, sendo selecionadas três áreas, uma a $3 \mathrm{~cm}$ da base da cauda, onde foram realizadas as medições do fluxo sanguíneo da pele sadia controle, outra a $7 \mathrm{~cm}$ e outra a $10 \mathrm{~cm}$, onde foram realizadas as queimaduras, sendo que as três áreas tiveram seu fluxo medido igualmente antes da produção das lesões.

A técnica utilizada para provocar as queimaduras no presente estudo foi adequada à metodologia descrita por Bayat e colaboradores ${ }^{16}$. Foi confeccionado um aparato com uma cânula de borracha acoplada de $5 \mathrm{~mm}$ de diâmetro para a saída do vapor. Para caracterizar uma queimadura de terceiro grau, foi realizado um estudo piloto onde, histologicamente, ficou determinada a profundidade da lesão de acordo com o tempo de exposição ao calor. Deste modo, com a mangueira posicionada perpendicularmente, manteve-se a cânula nos locais previamente marcados durante 5 segundos, onde foram realizadas as lesões conforme mostram as figuras 4.1 e 4.2 .
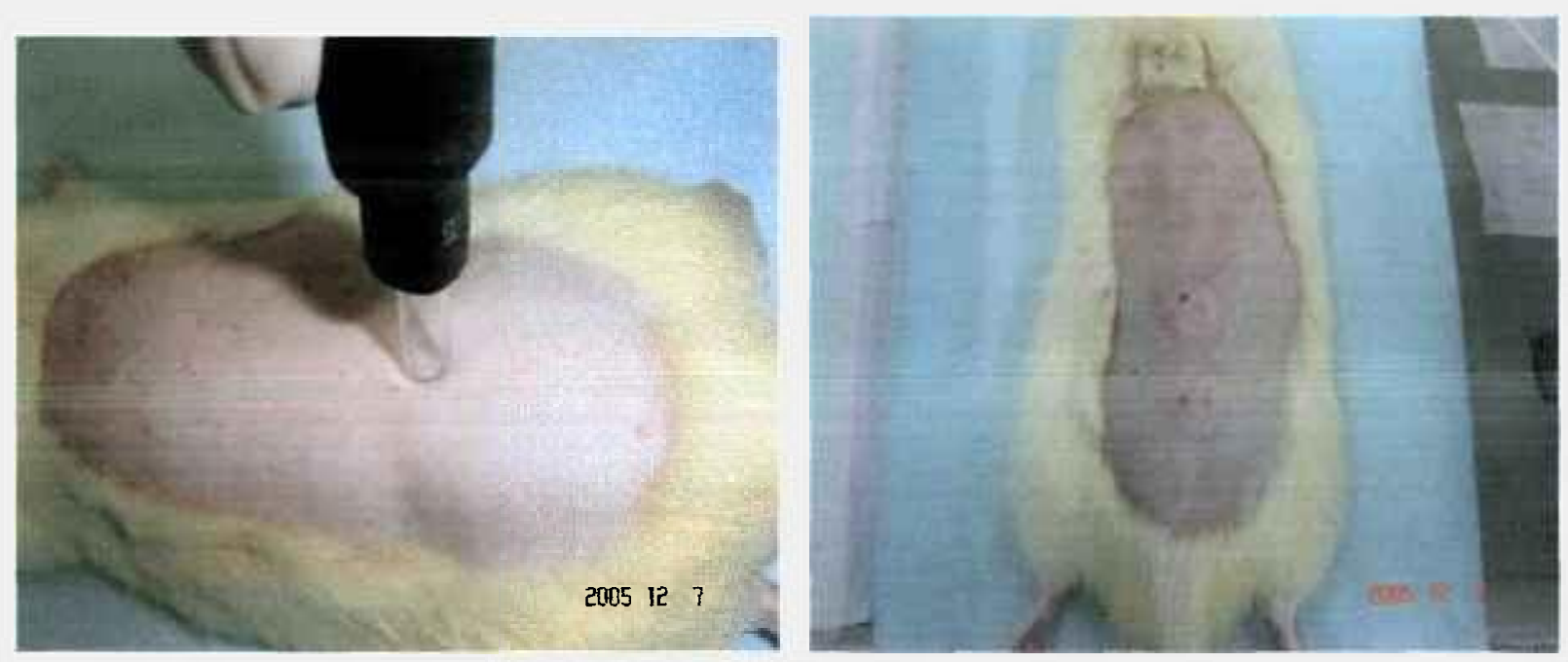
Os grupos foram separados de acordo com os tratamentos a serem realizados: grupo dose única (GU- 24 lesões) em 12 ratos, grupo dose fracionada (GF- 24 lesões) em 12 ratos e grupo controle sem tratamento (GC- 24 lesões) em 12 ratos.

O tratamento em cada grupo foi iniciado logo após a criação das lesões. O laser utilizado no presente estudo foi um diodo de arseneto de gálio e alumínio (BioWave LLLT Kondortec-São Carlos, Brasil), de emissão contínua, comprimento de onda de $660 \mathrm{~nm}$. A potência de saída de $30 \mathrm{~mW}$ foi aferida antes de cada irradiação com o uso de um medidor de potência calibrado (LaserCheck, Coherent, USA).

O GU foi irradiado com uma única dose de $4 \mathrm{~J} / \mathrm{cm}^{2}$ dia 1 (figura 4.3) e os animais do GF foram irradiados com $1 \mathrm{~J} / \mathrm{cm}^{2}$ nos dias $1,3,8$ e 10 . O GC prosseguiu sem tratamento para uma cicatrização espontânea até o término do experimento. A área irradiada foi de $1 \mathrm{~cm}^{2}$.

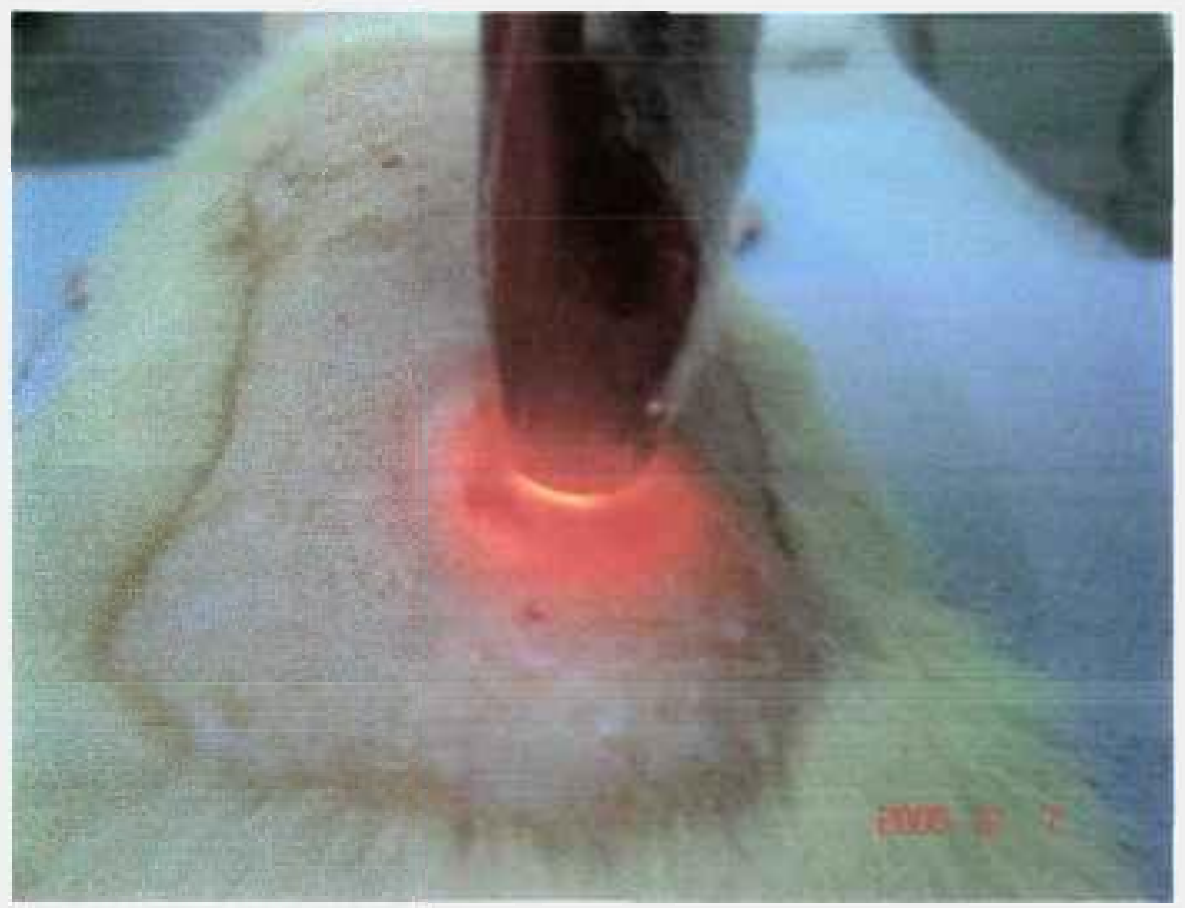

Figura 4.3 - Irradiação da queimadura com o laser de baixa potência. 
Para o monitoramento do fluxo sanguíneo, seguiu-se a metodologia proposta por Núñez et al $^{8}$. Foi utilizado o fluxômetro Flowlab com a sonda P13 de 1,5 mm de diâmetro emitindo em $\lambda=780 \mathrm{~nm}$, com potência $1 \mathrm{~mW}$ e com banda Doppler em $15 \mathrm{kHz}$.

A sonda do fluxômetro foi fixada através de um braço metálico a fím de se evitarem movimentos involuntários devido à manipulação da sonda, que pudessem afetar os resultados obtidos. O ajuste vertical da distância da sonda em relação à pele do animal foi padronizado por meio de uma película com $1 \mathrm{~mm}$ de espessura (figura 4.4).

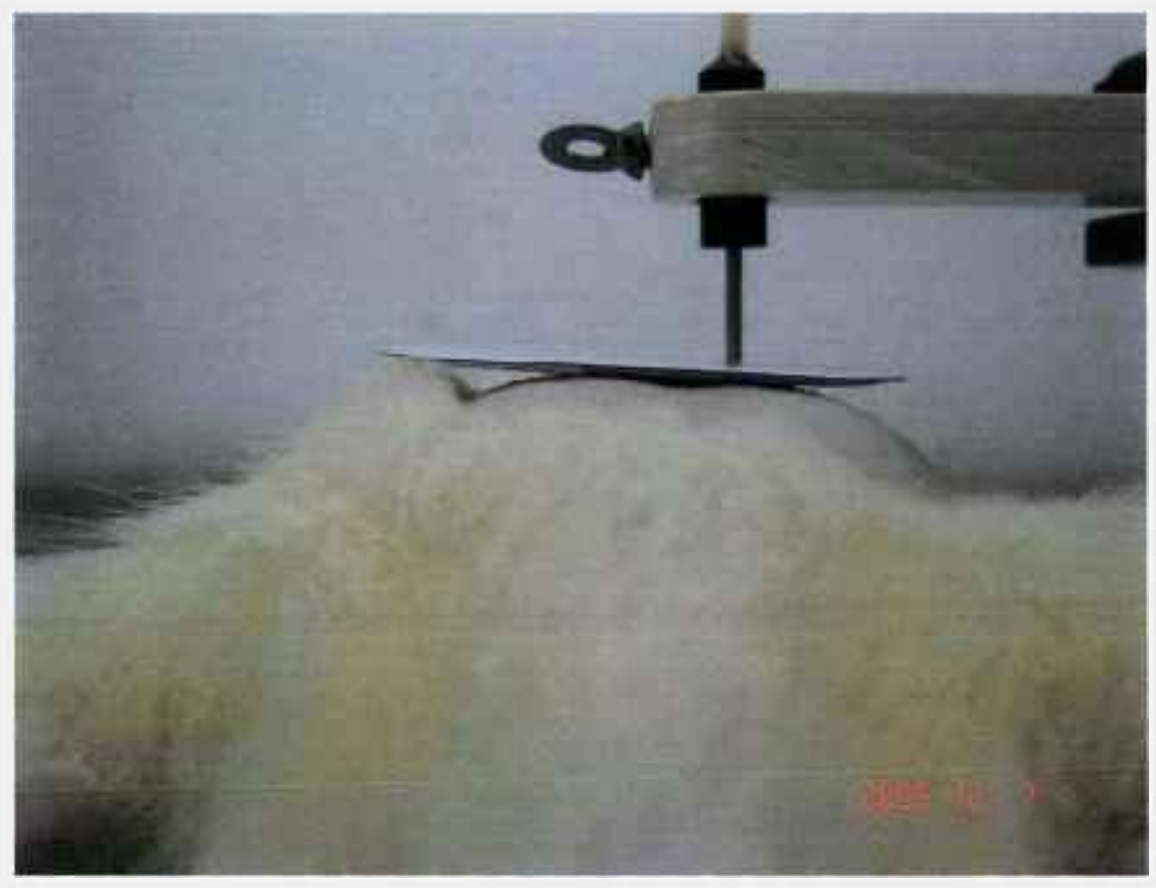

Figura 4.4 - Sonda posicionada sobre a pele do animal.

Com a sonda posicionada no sentido antero-posterior e vertical foram executadas as primeiras medidas de fluxo nas áreas determinadas, antes da realização de qualquer procedimento. Em cada área, foram realizados três registros distintos com $30 \mathrm{~s}$ de duração cada, totalizando $90 \mathrm{~s}$ para a leitura do fluxo. 
Para a análise de fluxometria, cada lesão foi monitorada nos dias 1, 3, 8, 10,15 e 21. O monitoramento do fluxo sangüíneo nos grupos irradiados foram realizados sempre após o tratamento com o laser de baixa potência. Os registros dos dados coletados foram armazenados em computador e analisados através do programa MoorSoft for Windows/moorLab v1.2, fornecido pelo fabricante do equipamento (figura 4.5).

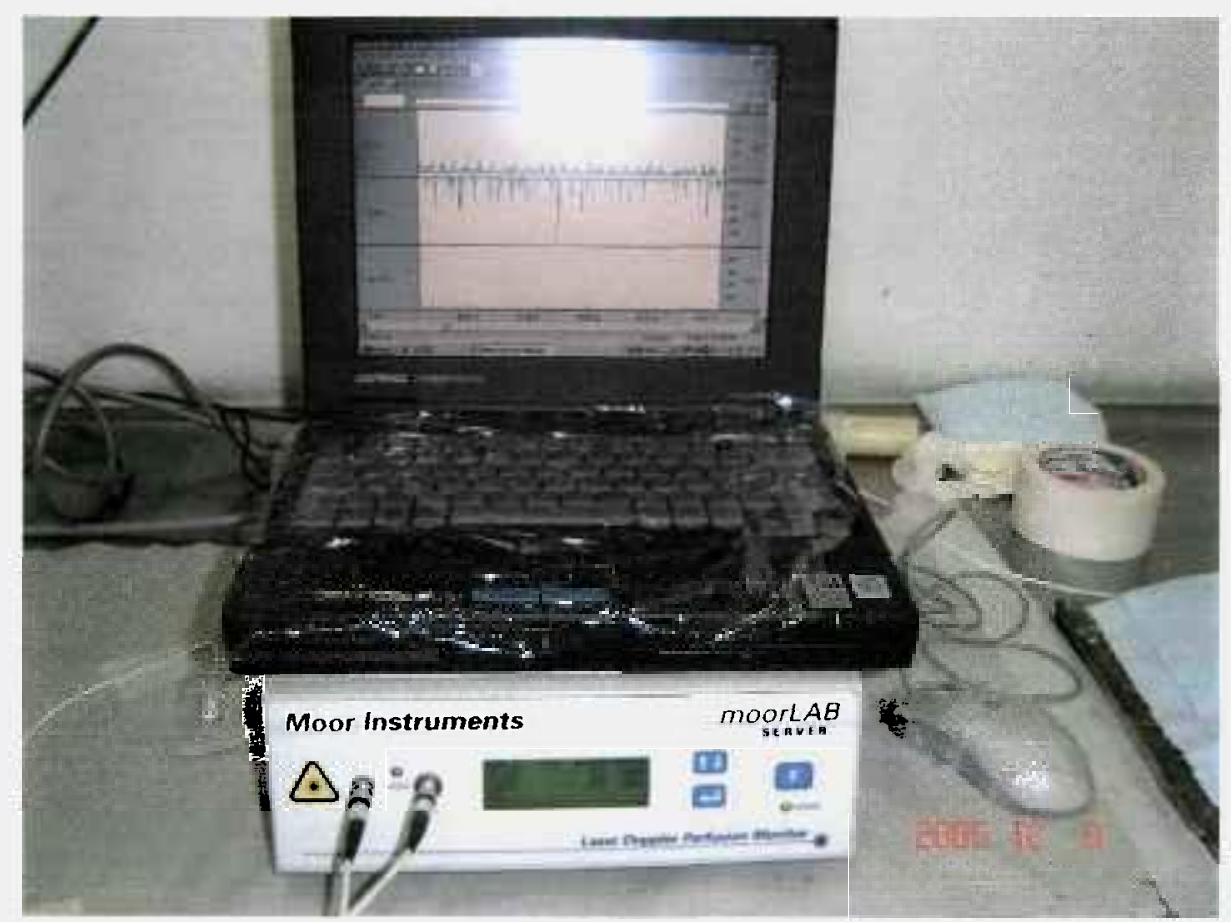

Figura 4.5 - Fluxômetro Laser Doppler

Para análise dos dados, seguiu-se a proposta de Núñez e colaboradores ${ }^{8}$. Em resumo, os valores obtidos para o fluxo são apresentados como mudanças percentuais do fluxo inicial obtidas no dia 1 , antes de realizar qualquer procedimento, o que significa que os dados obtidos no dia $\mathrm{d}=1$ da área sadia antes de realizar a queimadura (LS) e da pele sadia controle $(\mathrm{CS})$ foram computados como segue: $F(\%)=100\left(\mathrm{~F}_{\mathrm{LSd}} / \mathrm{F}_{\mathrm{CSd}}\right) / \mathrm{F}_{0}$, onde $\mathrm{F}_{\mathrm{LSd}} \mathrm{e}$ $\mathrm{F}_{\mathrm{CSd}}$ são as médias do fluxo de LS e CS em cada momento d, respectivamente. $\mathrm{F}_{0}$ é 
$\mathrm{F}_{\mathrm{LS}} / \mathrm{F}_{\mathrm{CS}}$, ambos medidos antes da queimadura (linha base $\left.=100 \%\right) . \mathrm{F}(\%)$ é, portanto, a média da porcentagem da variação do fluxo de LS referida à CS e às medidas no dia 1 . Os valores obtidos foram submetidos ao teste-t para análise estatística dos resultados. Os resultados foram considerados significantes quando $\mathrm{p}<0,05$.

Para a análise histológica, três animais por grupo foram sacrificados aleatoriamente em câmara de dióxido de carbono nos dia 3, 8, 10, 15 e 21 para obtenção de amostras de GF, GU e GC. Botões da pele foram cuidadosamente removidos por intermédio de uma tesoura reta, de tal forma que envolvesse parte da pele sadia adjacente à borda da ferida e o tecido lesionado em sua profundidade. As amostras foram mantidas em formaldeído a $10 \%$ por um período mínimo de $24 \mathrm{~h}$. Em seguida receberam o trâmite laboratorial de rotina. Os cortes histológicos obtidos foram corados com hematoxilina e eosina e analisados em um microscópio de luz (Leica DMLP, Alemanha). Foi realizada análise histológica semi-quantitativa dos eventos biológicos para avaliar a presença de tecido necrótico, infiltrado inflamatório, fibroblastos, vasos e tecido epitelial neoformado. Os resultados semi-quantitativos foram organizados de acordo com o seguinte escore: 0ausente; 1- leve; 2- moderado; 3 - intenso. Sendo que leve significa $25 \%$ de presença da estrutura estudada, moderado presença de $50 \%$ e intenso acima de $75 \%$.

Para análise quantitativa, foi realizada a contagem de vasos sangüíneos neoformados na derme superficial. As imagens foram capturadas através do microscópio óptico (Leica DMLP, Alemanha) e analisadas no programa Image $J$ versão $1.34 \mathrm{~s}$ (disponível em www.uhnresearch.ca). As fotomicrografias foram reticuladas para selecionar três áreas distintas padronizando a contagem de vasos em cada lâmina estudada. 
Foram contados os vasos neoformados na derme superficial, imediatamente abaixo da borda superior: 1- área na extremidade direita, 2- área central, 3- área na extremidade esquerda (Figuras 4.6 e 4.7). Os valores obtidos foram submetidos ao teste-t para análise estatística dos resultados. Os resultados foram considerados significantes quando $\mathrm{p}<0,05$.

Para estabelecer uma referência na quantificação de vasos neoformados, foram examinadas três amostras de pele de rato sadia em corte histológico. Os vasos sangüíneos presentes na derme superficial foram contados no mesmo padrão descrito anteriormente.

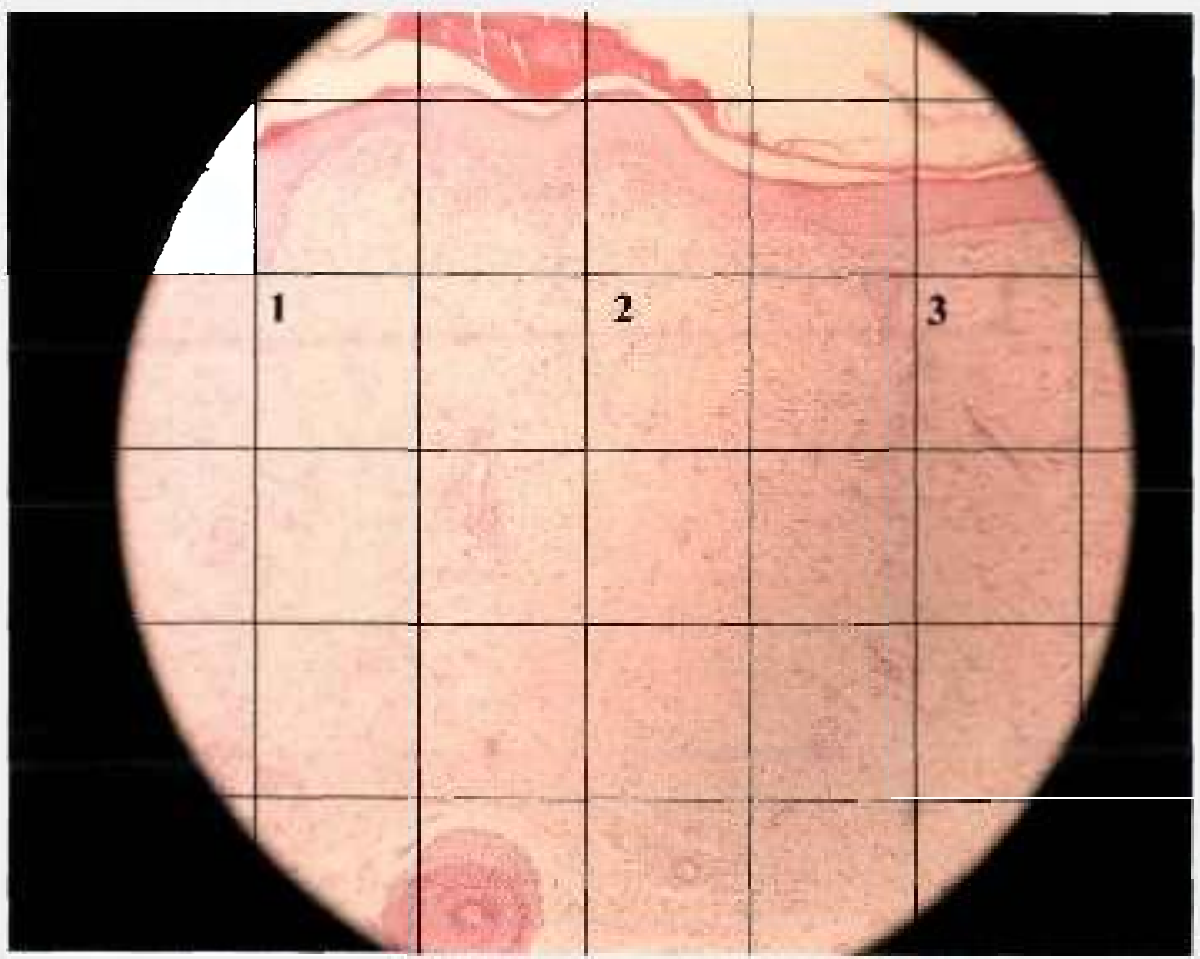

Figura 4.6 - Imagem reticulada de pele de rato do GU dia 15 para contagem de vasos sangüíneos (Áreas 1, 2 e 3). HEX100. 


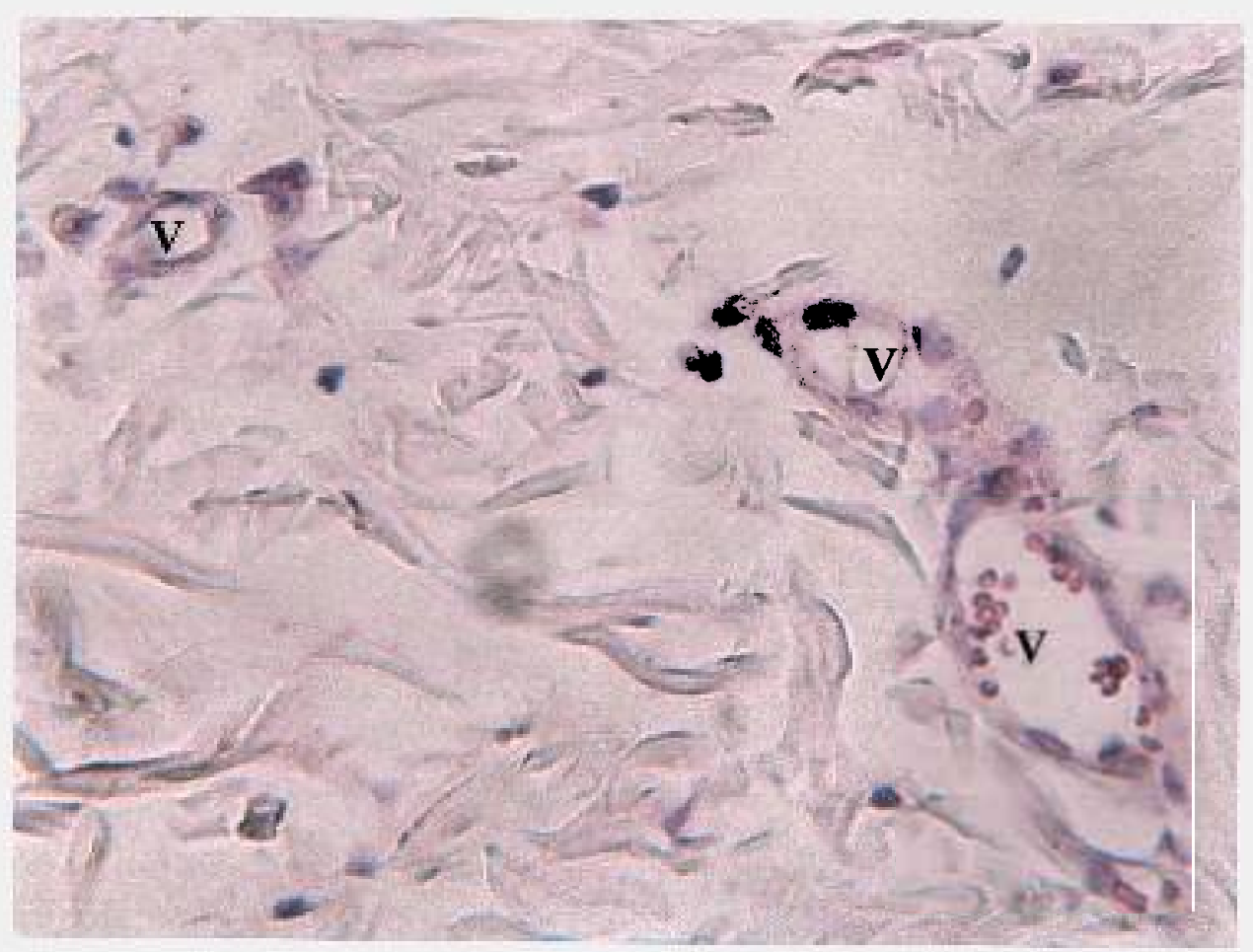

Figura 4.7 - Fotomicrografia de pele de rato com vasos sangüíneos neoformados (V). HEX400. 


\section{5 - RESULTADOS}

\section{1 - Análise da fluxometria laser Doppler}

A figura 5.8 apresentam os valores médios obtidos da variação da porcentagem do fluxo sangüíneo em relação ao dia 1 do experimento durante todo o período experimental.

Nos grupos estudados, foram encontradas evidências estatísticas suficientes $(p<0,05)$ para inferir que os valores médios das variações percentuais de fluxo nos dias $8 \mathrm{e}$ 10 são superiores a 100\%, significando acréscimo de fluxo nestes momentos.

Somente foram encontradas evidências suficientes, para $p<0,05$, para inferir que os valores médios das variações percentuais de fluxo são diferenças entre o GC e os GU e GF no dia 21. Não foram encontradas evidências suficientes para saber se há diferença de fluxo em qualquer outro momento entre os grupos. Com relação aos grupos GF e GU, nenhuma diferença estatística significante foi observada em qualquer um dos periodos analisados.

Os intervalos de confiança dos valores médios das variações percentuais de fluxo de cada momento investigado de cada grupo, construídos usando distribuições t-student, para significância 95\%, são apresentados no quadro 3. 
Quadro 3: Intervalos de confiança dos valores médios das variações percentuais de fluxo de cada momento investigado de cada grupo.

\begin{tabular}{|l|l|}
\hline GC1 & $100.000-100.000$ \\
\hline GC3 & $62.5-113.7$ \\
\hline GC8 & $148.4-250.5$ \\
\hline GC10 & $103.2-219.9$ \\
\hline GC15 & $67.6-177.7$ \\
\hline GC21 & $62.82-102.73$ \\
\hline GU1 & $100.000-100.000$ \\
\hline GU3 & $81.0-147.3$ \\
\hline GU8 & $188.4-300.5$ \\
\hline GU10 & $147.1-251.6$ \\
\hline GU15 & $103.7-242.5$ \\
\hline GU21 & $86.1-165.2$ \\
\hline GF1 & $100.000-100.000$ \\
\hline GF3 & $70.25-93.50$ \\
\hline GF8 & $206.7-333.8$ \\
\hline GF10 & $124.2-292.0$ \\
\hline GF15 & $90.3-155.2$ \\
\hline GF21 & $99.8-185.9$ \\
\hline
\end{tabular}




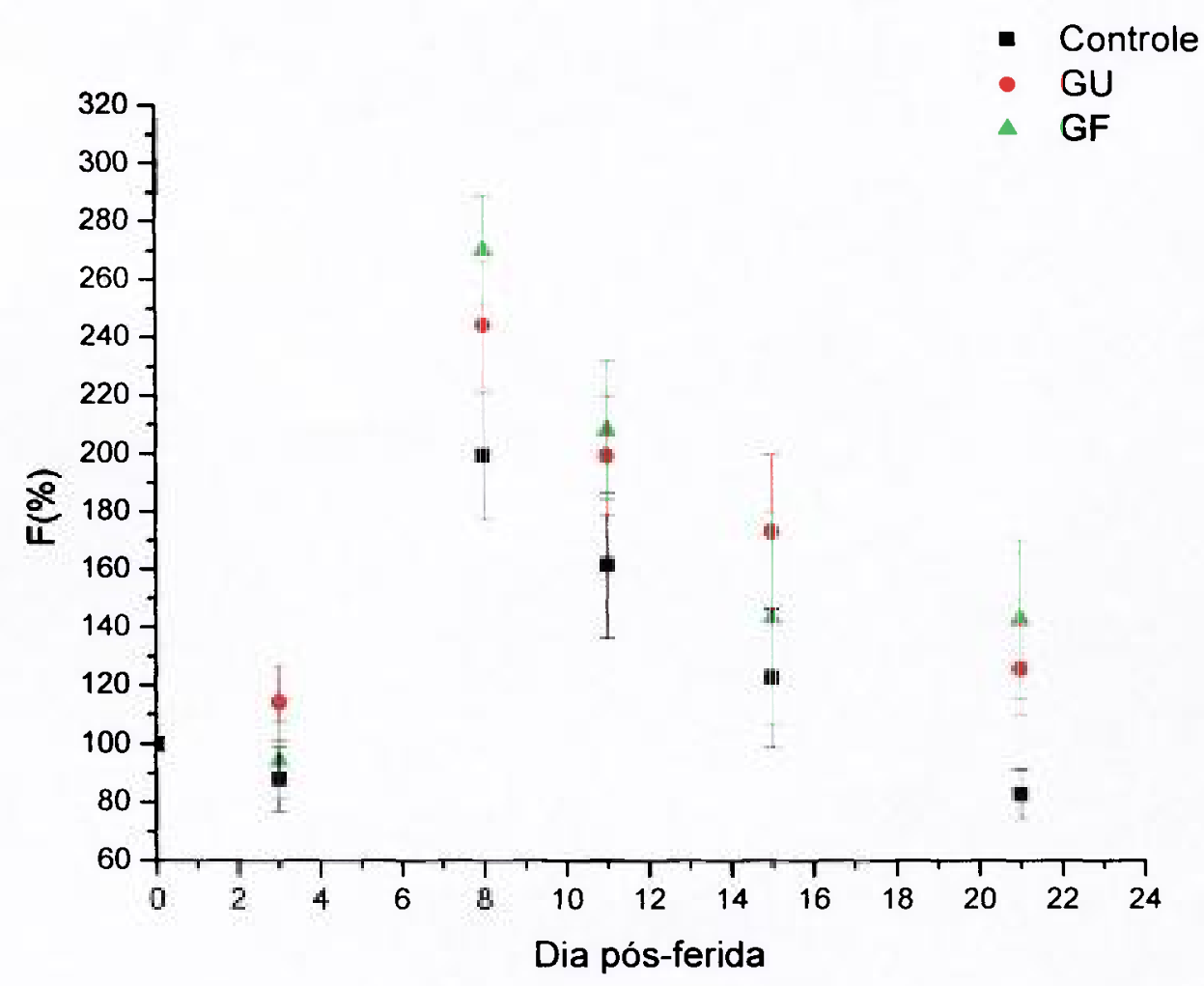

Figura 5.8: Valores médios \pm erro padrão da porcentagem do fluxo sangüíneo em relação ao dia 1 do experimento durante o período experimental. 


\section{2 - Análise histológica}

Os resultados obtidos na análise histológica mostraram que o processo de cicatrização varia entre os grupos irradiados e o controle. Entretanto, não foram observadas diferenças significantes entre os grupos irradiados. O quadro 1 é uma representação semiquantitativa dos principais achados durante todo o período experimental. Os resultados foram organizados de acordo com o seguinte escore: 0 - ausente; 1 - leve; 2 - moderado; 3 - intenso.

No dia 3 foram observadas, nas amostras irradiadas e controle, uma variedade de células inflamatórias e restos de células, caracterizando necrose (figura 5.1). Não foi observado presença de fíbroblastos ativos nos grupos irradiados e controle. Com relação à angiogênese, nenhum grupo estudado apresentou neoformação de vasos. Tanto nas áreas irradiadas, quanto nas não-irradiadas, a região lesada estava desprovida de epiderme.

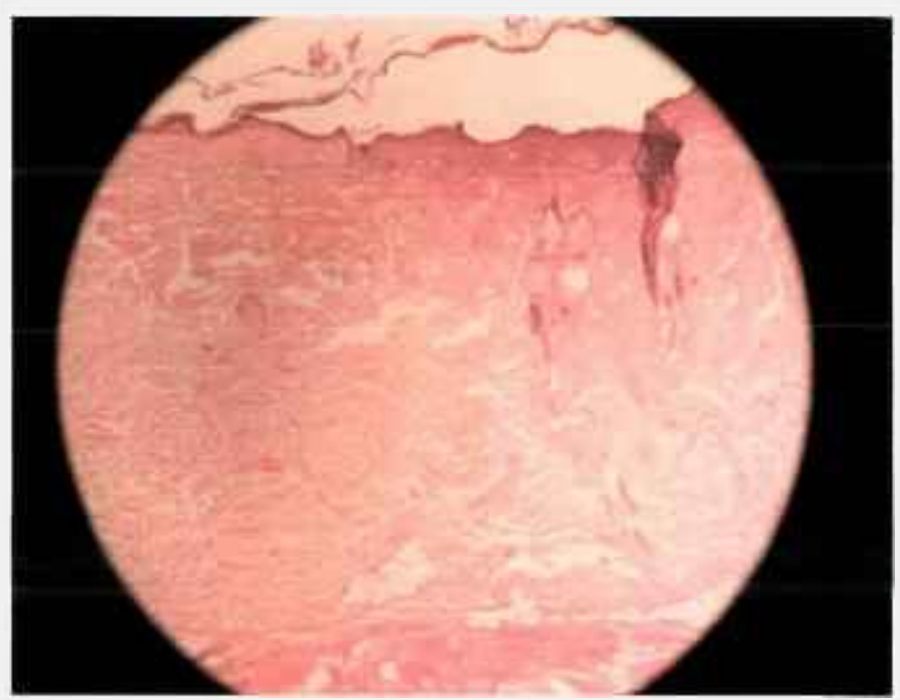

Figura 5.1: Fotomicrografia de pele de rato do GF, 3 dias após a criação da queimadura. Observa-se necrose em toda extensão da derme. HEX100. 
No dia 8 , os grupos irradiados e o controle ainda apresentaram grande quantidade de tecido necrótico e infiltrado inflamatório. Neste dia os grupos apresentaram igual atividade fibroblástica e início de neoformação vascular.

No dia 10 foram observadas algumas diferenças morfológicas na área lesionada, quando os grupos irradiados e o controle foram comparados. Os animais irradiados mostraram início de repitelização nas bordas das feridas, enquanto o grupo controle não apresentava indícios de repitelização. Nos grupos irradiados em ambos os lados da ferida, a camada epitelial havia migrado sobre um tecido conjuntivo frouxo que continha fibroblastos ativos, formados na derme subjacente durante o período de reparação. Foi observada grande quantidade de tecido necrótico no controle enquanto que nos grupos irradiados esta camada se apresentou menos espessa (figuras 5.2 e 5.3). A derme subjacente apresentou angiogênese moderada nos grupos irradiados e controle. Foi constatada maior presença de fibroblastos nos grupos irradiados em relação ao controle.

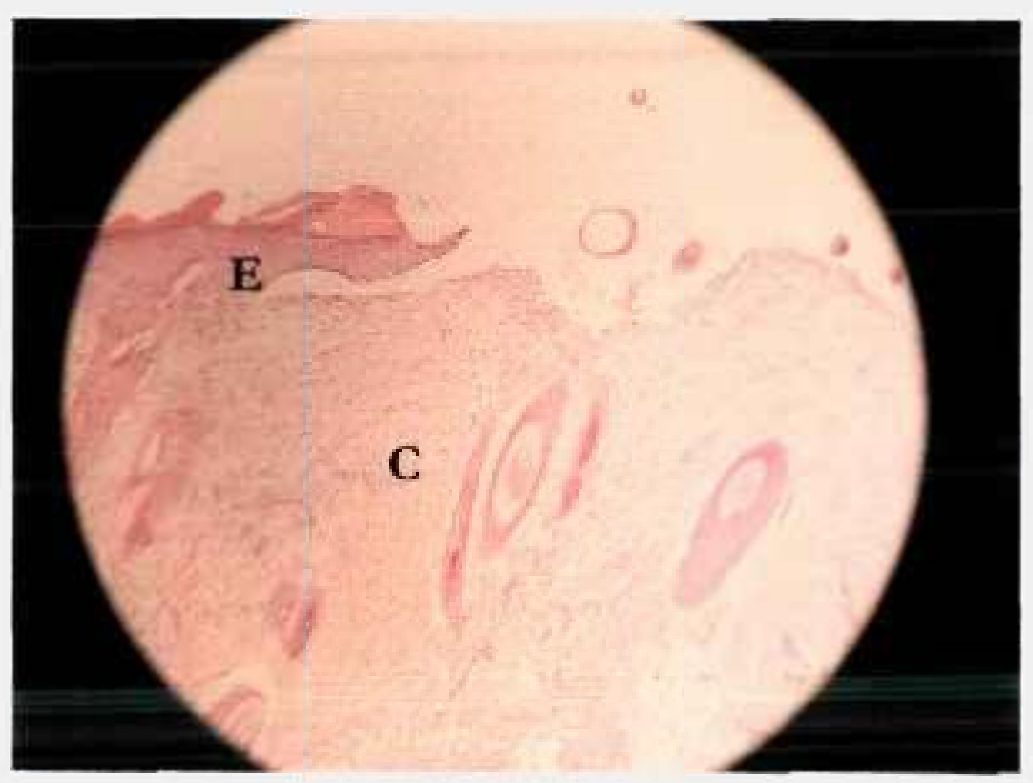

Figura 5.2: Fotomicrografia de pele de rato do GF 10 dias após a criação da queimadura. Camada epitelial migrando na borda da ferida (E) e tecido conjuntivo (C) com grande quantidade de fibroblastos e moderada angiogênese. HEX100. 


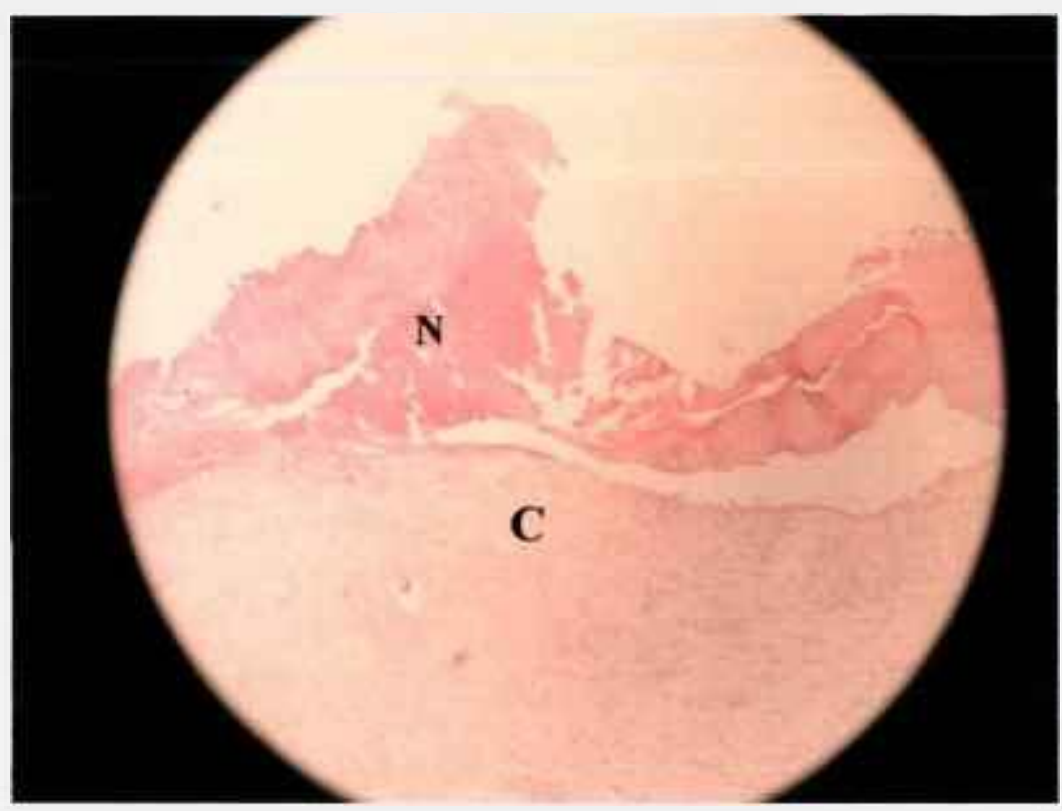

Figura 5.3: Fotomicrografia de pele de rato do GC 10 dias após a criação da queimadura. Observa-se ausência de reepitelização e tecido conjuntivo (C) frouxo caracterizado por intenso infiltrado inflamatório. Tecido necrótico intenso ( $\mathbf{N})$, HEX100.

No dia 15, os grupos irradiados e controle apresentaram resultados semelhantes em relação a leve presença de infiltrado inflamatório. Uma intensa neoformação de vasos sanguíneos foi observada, sendo que esta alteração foi mais evidente nos grupos irradiados. A atividade fibroblástica nos grupos irradiados foi mais expressiva em relação ao controle. Neste dia o grupo controle ainda apresentava camada de tecido necrótico mais espessa quando comparado aos grupos irradiados (figuras 5.4 e 5.5). 


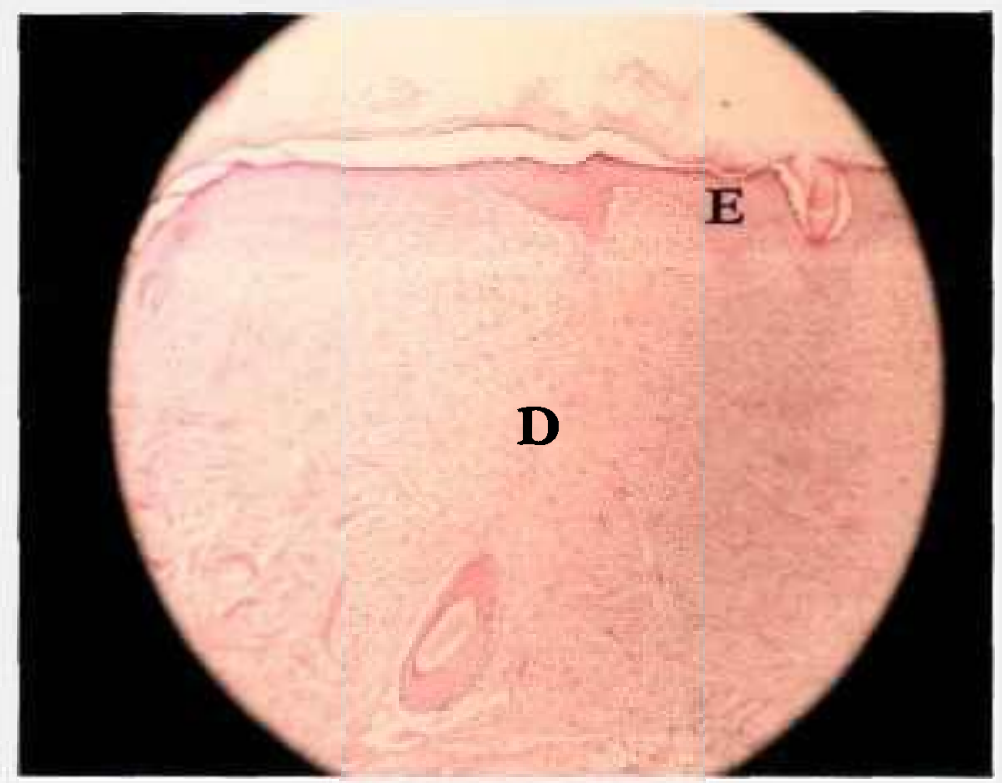

Figura 5.4: Fotomicrografia de pele de rato do GF 15 dias após a criação da ferida. Observa-se grande presença de vasos neoformados na derme superficial (D) e tecido epitelial recobrindo toda a área lesada. HEX100. 


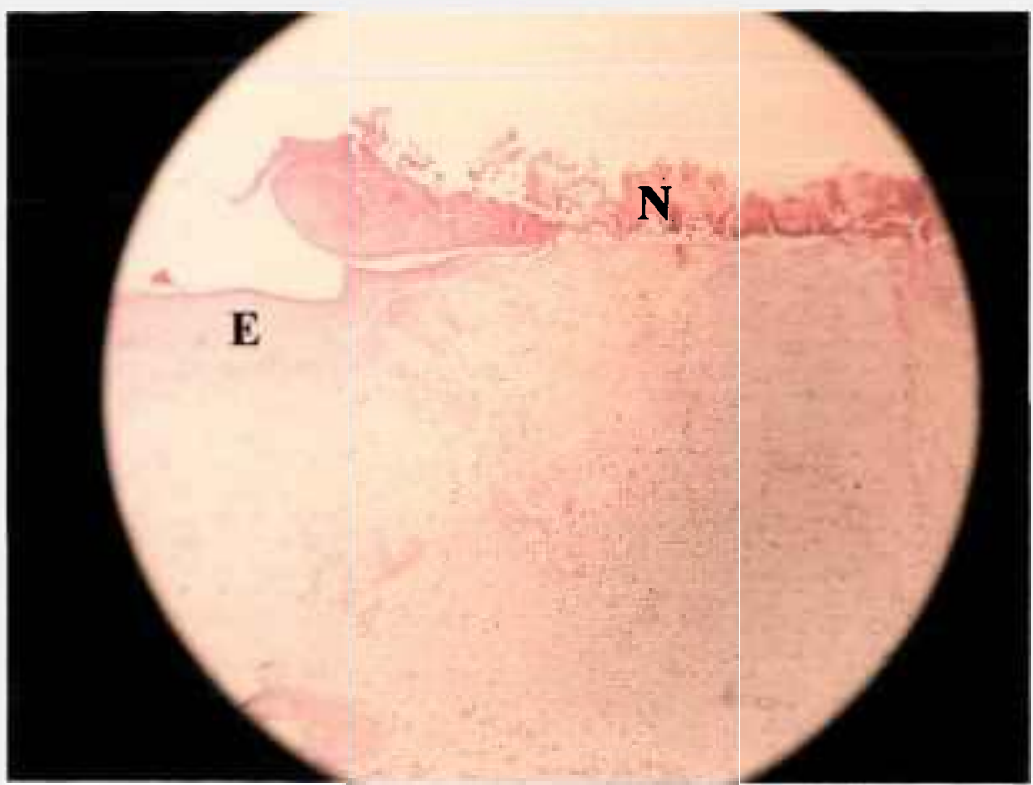

Figura 5.5: Fotomicrografia de pele de rato do GC 15 dias após a criação da ferida. Observa-se a epiderme (E) cobrindo parte da área lesionada com presença moderada de tecido necrótico (N). HEX100.

Após 21 dias do início do experimento, os cortes histológicos mostraram a superficie da pele que havia sido queimada completamente recoberta por uma nova camada epitelial. A derme reparada foi formada por tecido conjuntivo frouxo composto principalmente de fibroblastos. Não houve diferenças significantes entre os grupos irradiados e controle em relação a repitelização (figura 5.6). Neste momento o grupo controle apresentava maior neovascularização com menor proliferação de fibroblastos quando comparados aos grupos irradiados. 


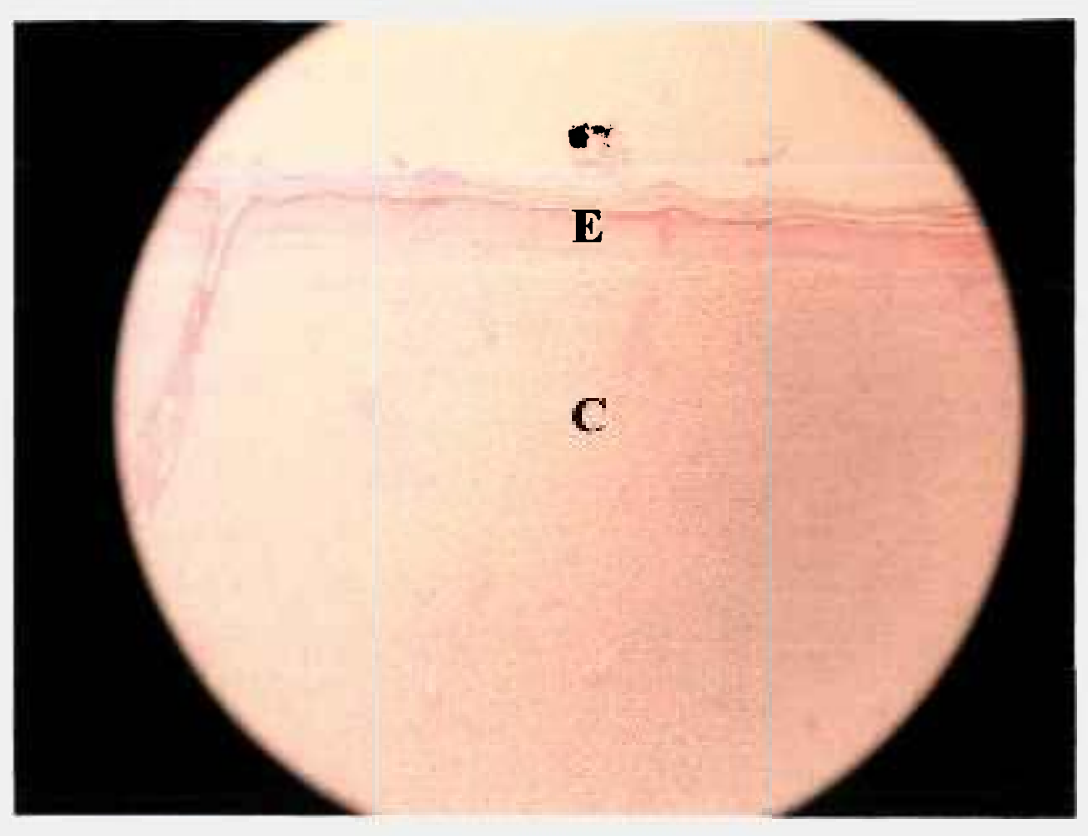

Figura 5.6: Fotomicrografia de pele de rato do GU 21 dias após a criação da queimadura. Nota-se tecido epitelial (E) diferenciado e tecido conjuntivo (C) frouxo com fibroblastos ativos e vasos neoformados. HEX100. 
Quadro 1: Representação semi-quantitativa do processo de cicatrização de queimaduras de pele de rato durante o período experimental.

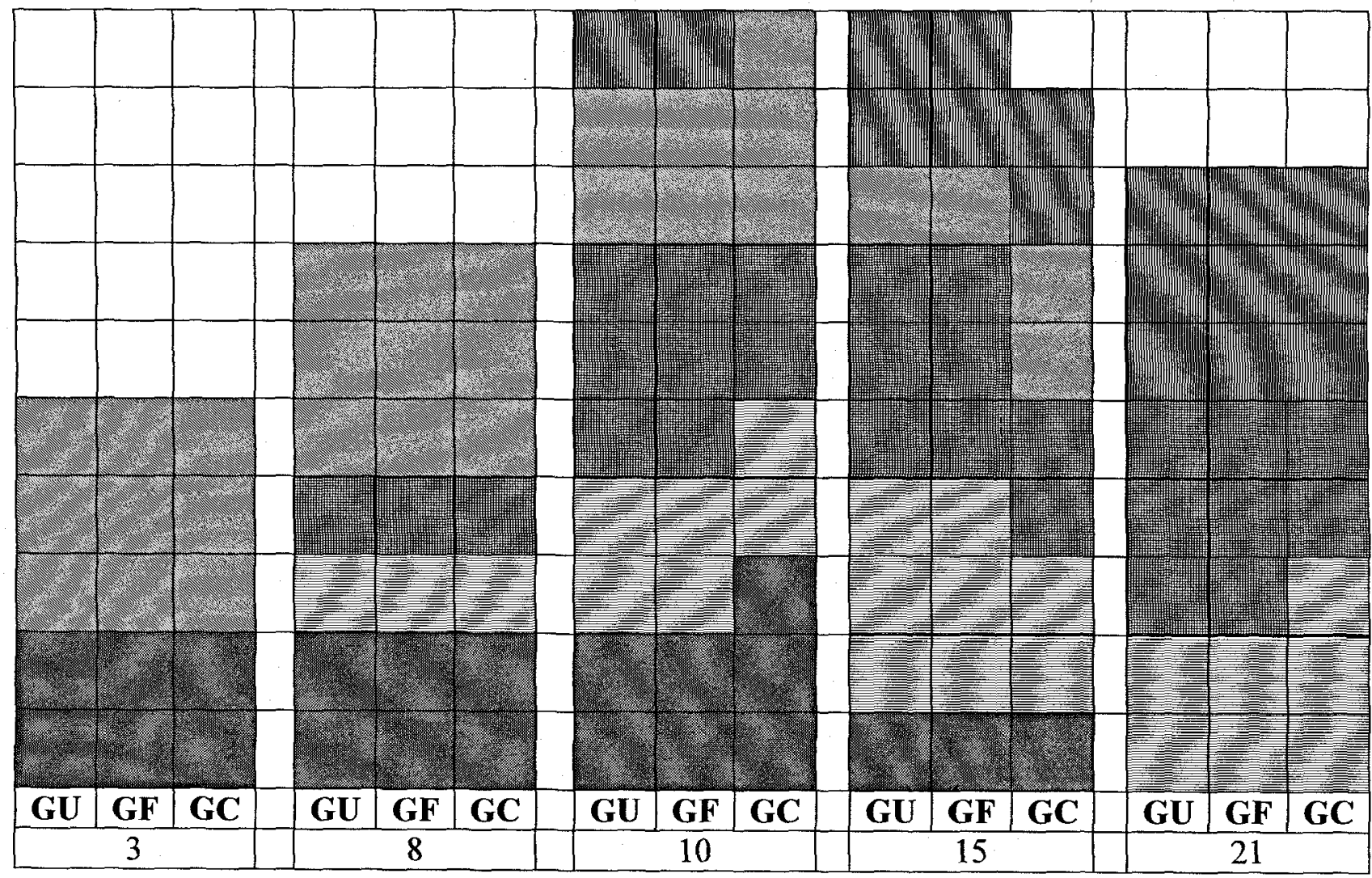

Dias pós-criação das queimaduras

\begin{tabular}{|l|l|}
\hline & $\begin{array}{l}\text { Infiltração polimorfonuclear } \\
\text { Neovascularização }\end{array}$ \\
\hline & Proliferação de fibroblastos \\
Tecido necrótico \\
Epitelização
\end{tabular}

Estruturas analisadas

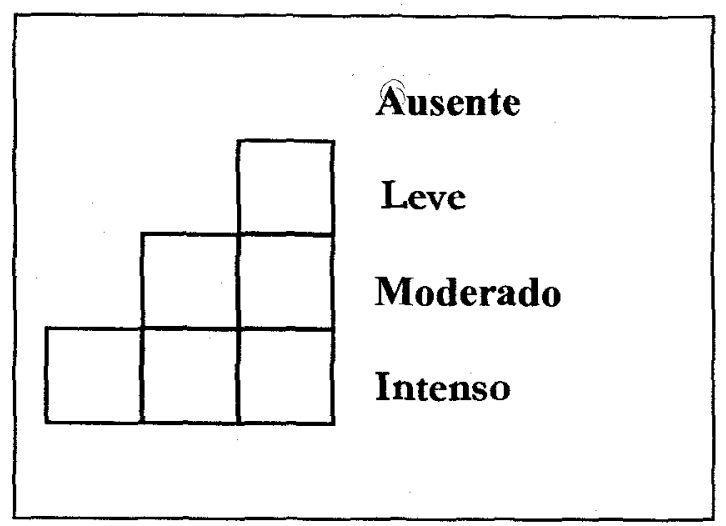

Escore 
$\mathrm{Na}$ análise quantitativa de vasos sangüíneos neoformados, os grupos irradiados e controle apresentaram o mesmo comportamento nos dia 1, 3, 8, 10 e 15, com número crescente a cada dia analisado. Entretanto, os grupos irradiados tiveram seu pico no dia 15 , decrescendo no dia 21. Por outro lado, o grupo controle, continuou em curva ascendente até o dia 21 (figura 5.7).

Foram encontradas evidências estatísticas suficientes $(p<0,05)$ para inferir que os valores médios das variações percentuais de crescimento de vasos nos dias $8,10,15$ e 21 são superiores a $0 \%$, significando acréscimo de vasos nestes momentos. Não foram encontradas evidências suficientes para saber se há diferença de quantificação de vasos nos outros momentos.

Somente foram encontradas evidências suficientes, para $p<0,05$, para inferir que os valores médios das variações percentuais de crescimento de vasos são diferenças entre os GC e GU no 21 dia e entre os GC e GF nos dias 10 e 21 . Não foram encontradas evidências suficientes para saber se houve diferença quantitativa de vasos em qualquer outro momento entre grupos.

Para pele sadia, o valor médio dos vasos contados foi 17. 


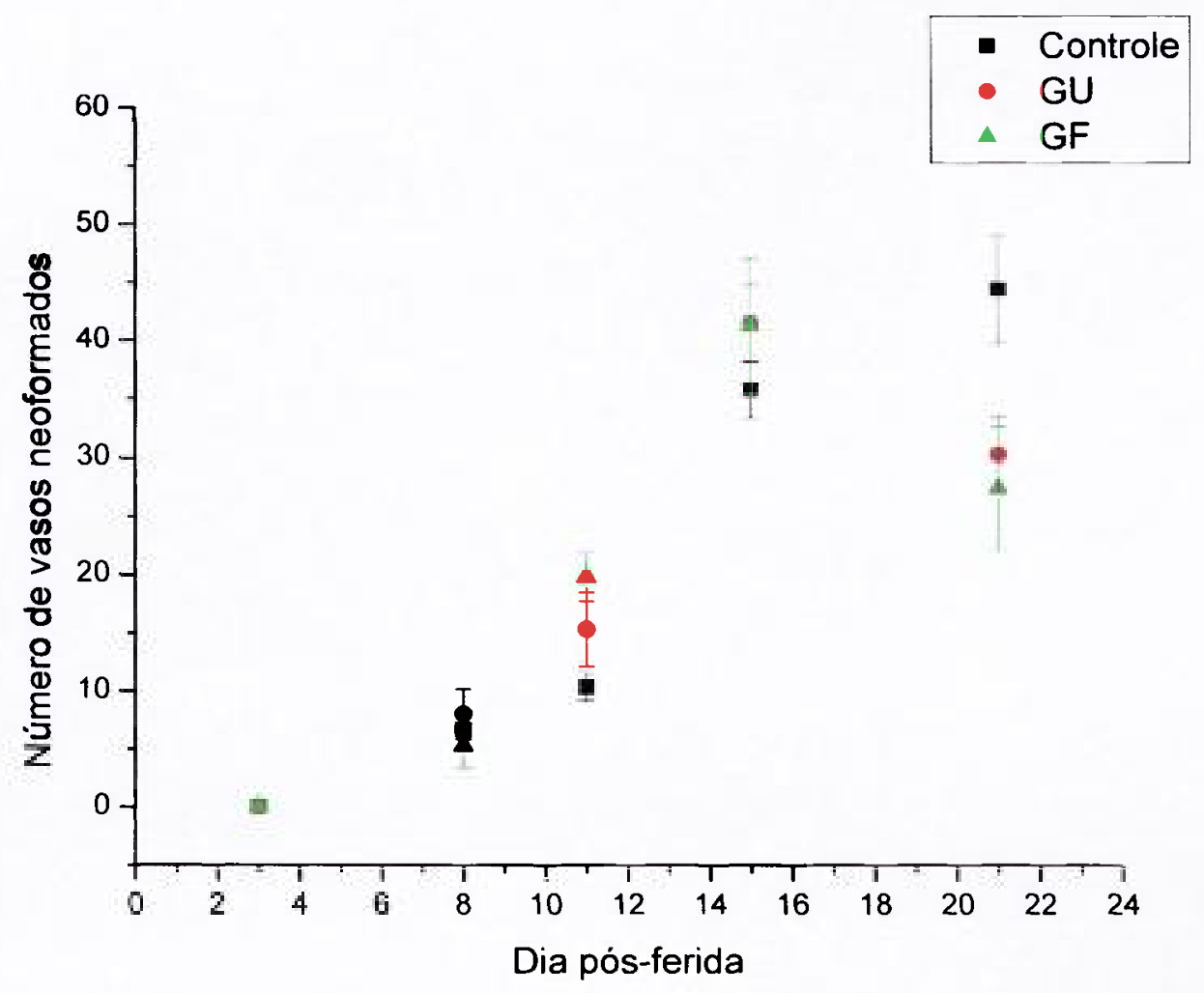

Figura 5.7: Valores médios \pm desvio padrão do número de vasos neoformados durante o período experimental. Foram contados três quadrados na derme superficial em três lâminas histológicas de cada grupo experimental.

Os intervalos de confiança dos valores médios do número de vasos neoformados de cada momento investigado de cada grupo, construídos usando distribuições t-student, para significância 95\%, são apresentados no quadro 2 . 
Quadro 2: Intervalos de confiança dos valores médios do número de vasos neoformados para cada momento investigado de cada grupo.

\begin{tabular}{|l|l|}
\hline GC1 & 000 \\
\hline GC3 & 000 \\
\hline GC8 & $2.21-9.56$ \\
\hline GC10 & $7.19-12.59$ \\
\hline GC15 & $28.92-40.19$ \\
\hline GC21 & $31.02-52.98$ \\
\hline GU1 & 000 \\
\hline GU3 & 000 \\
\hline GU8 & $2.26-11.96$ \\
\hline GU10 & $8.52-21.48$ \\
\hline GU15 & $32.67-47.77$ \\
\hline GU21 & $20.74-36.37$ \\
\hline GF1 & 000 \\
\hline GF3 & 000 \\
\hline GF8 & $1.58-9.31$ \\
\hline GF10 & $15.64-24.14$ \\
\hline GF15 & $27.36-52.19$ \\
\hline GF21 & $15.10-37.34$ \\
\hline
\end{tabular}




\section{6- DISCUSSĀO}

Ao longo dos anos, têm sido constantes na literatura estudos que procuram avaliar os efeitos de fotoestimulação da terapia com laser em baixa intensidade em uma variedade de condições patológicas, incluindo cicatrização de lesões cutâneas como queimaduras.

Diversos modelos animais têm sido utilizados para se avaliar o processo de reparo de feridas cutâneas. Dentre eles têm-se o rato $^{8,16,29}$ porco $^{30}$ e o cavalo ${ }^{31}$. No presente estudo foi utilizado o rato, por se tratar de um animal de pequeno porte, com elevada resistência orgânica, de fácil manuseio cirúrgico, fácil reprodução e muito utilizado em pesquisas.

As queimaduras profundas de pele têm sido foco de inúmeras pesquisas nas últimas décadas, pois causam extremo dano às vítimas, tanto física, quanto psiquicamente. A demora na cicatrização das lesões de queimadura de terceiro grau é o grande problema no tratamento deste trauma, que ainda possui alta taxa de mortalidade decorrente de infecções secundárias ${ }^{17,32,33}$. De acordo com Joseph et $a l^{36}$, queimaduras por calor são $85 \%$ das injúrias térmicas ocorridas em crianças, levando $60 \%$ destas à unidade de tratamento intensivo ${ }^{34}$.

Para este estudo foram realizadas duas queimaduras de terceiro grau no dorso de ratos com uma fonte de vapor de água, adequando a metodologia proposta por Bayat et. $a l^{16}$. 
Para caracterizar uma queimadura de terceiro grau e padronizar o número de lesões que tivessem a mesma característica na pele do dorso de rato, foi realizado um estudo piloto expondo a superficie dorsal do rato em contato com uma fonte de vapor de água fervente durante 3,5 e 10 segundos. Foram produzidas três lesões na linha da coluna vertebral, uma mais próxima ao pescoço (L1), uma na altura média do tronco (L2) e outra próxima da cauda (L3). As amostras foram analisadas histologicamente confirmando que o tempo de $5 \mathrm{~s}$ foi suficiente para produzir uma lesão de epiderme e total da derme, caracterizando uma queimadura de terceiro grau. No grupo L1, as lesões não se apresentaram de forma homogênea quando comparadas às L2 e L3. Sendo assim, para realização deste estudo foram produzidas duas lesões por animal sendo uma na linha média e outra mais caudal.

Os grupos foram divididos de acordo com o tratamento a ser realizado, para avaliar os efeitos da irradiação em relação à dose. Um grupo foi tratado com dose fracionada de $1 \mathrm{~J} / \mathrm{cm}^{2}$ em aplicações intervaladas (dias 1, 3, 8 e 10). Outro grupo foi irradiado com uma única dose de $4 \mathrm{~J} / \mathrm{cm}^{2}$ no dia 1 . Nosso objetivo foi verificar os efeitos destes parâmetros de tratamento uma vez que alguns autores sugerem que a dose é acumulativa $^{9,10}$ e outros que os efeitos são acumulativos ${ }^{6}$.

Para análise dos dados obtidos, foi realizado um estudo histológico semiquantitativo, observando as diferenças morfológicas das estruturas da pele nas fases do processo de reparação e quantitativo, com a contagem de vasos sangüíneos neoformados na derme superficial. E ainda, monitoramento do fluxo sanguíneo, uma vez que a vascularização apresenta grande importância neste processo. 
Neste trabalho, as irradiações fracionadas foram realizadas nos dias 1, 3, 8 e 10 . O objetivo destas irradiações foi agir em momentos específicos do processo de reparo, uma vez que no dia 1, a fase inflamatória é o alvo mais provável; no dia 3 , seria a fase inflamatória e um possível início da fase proliferativa; no dia 8, a fase proliferativa está em franca atividade, e no dia 10 , ainda na fase proliferativa e início da fase de remodelação seria o esperado ${ }^{13}$. A dose única de $4 \mathrm{~J} / \mathrm{cm}^{2}$ foi aplicada no dia 1 , buscando assim observar os possíveis efeitos desta irradiação na biomodulação da fase inflamatória.

De acordo com a análise semi-quantitativa, não foram observadas diferenças entre os grupos controle e irradiados nos dias 3 e 8 . As diferenças entre os grupos irradiados e controle começaram ser notadas no dia 10 , coincidindo com a fase proliferativa do processo cicatricial. Neste dia os grupos irradiados apresentaram reepitelização nas bordas da ferida, enquanto no grupo controle não foi observado a presença de neoformação epitelial. Este dado é de extrema importância, uma vez que os grupos irradiados apresentaram restabelecimento adiantado do tecido epitelial, o que pode representar menor susceptibilidade à contaminação e infecção atrasando o processo de reparo $^{17,18,19}$

Um panorama geral do dia 10 mostrou que os grupos irradiados apresentaram maior quantidade de fibroblastos e neoformação epitelial enquanto o GC apresentou maior quantidade de infiltrado inflamatório e tecido necrótico. Este panorama demonstra claramente que os grupos irradiados encontram-se em fase proliferativa enquanto o GC encontra-se entre as fases inflamatória e proliferativa. Estes resultados concordam com outros trabalhos da literatura, onde os aspectos da cicatrização tecidual são demonstrados 
em relação à proliferação fibroblástica, a síntese de colágeno, a estimulação de macrófago e o aumento na taxa de produção de matriz extracelular e aceleração da reepitelização ${ }^{31}$.

No $15^{\circ}$ os grupos irradiados se diferenciaram do controle em relação à presença de tecido necrótico. O grupo controle ainda apresentava moderada quantidade de tecido necrótico, enquanto que nos grupos irradiados esta camada já estava sendo substituída por tecido conjuntivo com grande quantidade de fibroblastos e neoformação vascular. Estes dados sugerem que, apesar do grupo controle e irradiados apresentarem o mesmo comportamento em relação à neoformação epitelial, os grupos irradiados apresentaram um tecido conjuntivo frouxo em fase cicatricial mais avançada, com grande quantidade de fibroblastos, quando comparado ao dia 10 e ao grupo controle o que concorda com trabalhos que descrevem o aumento significativo de fibroblastos em lesões irradiadas com laser em baixa intensidade ${ }^{26,35}$.

Ao final do experimento, no dia 21 , todos os grupos apresentaram reparação cutânea completa, com as lesões cobertas por tecido epitelial e tecido conjuntivo remodelado. $\mathrm{O}$ número de vasos neoformados nos grupos irradiados diminuiu, conforme o esperado, enquanto que o grupo controle mostrou ainda moderada formação vascular, o que sugere a continuidade no processo de reparação quando comparado aos grupos irradiados. A mais expressiva proliferação de fibroblastos foi observada nos grupos irradiados, esta atividade fibroblástica mais intensa pode estar ligada à maturação e remodelação da matriz colágena o que confere resistência à pele neoformada ${ }^{36,37}$.

Independente da dose utilizada, os efeitos benéficos da terapia foram observados no dia 10, considerando os critérios de neoformação epitelial e proliferação de fibroblastos. 
Neste momento ocorre a entrada na fase proliferativa do reparo. Este resultado concorda com o trabalho de Conlan et al que afirmam que a cicatrização tecidual ocorre em três fases: a fase inflamatória, a fase proliferativa e a fase de remodelamento, sendo que, segundo esses autores, a maioria dos relatos sobre bioestimulação do laser sugere que seu maior efeito ocorre durante a fase proliferativa ${ }^{37}$. De fato, foi realizada a contagem de vasos sangüíneos em pele de rato sadia para confrontar os resultados obtidos nas fases de reparo tecidual em relação aos três grupos estudados do experimento, uma vez que após o período de reparação tecidual, na fase de remodelamento, a formação vascular tende a estabilizar e retornar próxima aos níveis iniciais ${ }^{17}$. Na contagem dos vasos neoformados foi observado que os grupos irradiados apresentaram no dia 21 menor número de vasos em relação ao dia 15 e ao grupo controle, porém, sem diferenças significantes entre si. Os grupos irradiados apresentaram resultados mais próximos aos da pele sadia, contrariamente ao grupo controle que apresentou uma quantidade ainda elevada de vasos neoformados neste dia. Este resultado confirma que a irradiação com laser em baixa intensidade, nos parâmetros utilizados neste estudo, promoveu aceleração da cicatrização cutânea.

A análise do número de vasos apontou diferença entre GF e GC no dia 10, o mesmo não foi observado entre GU e GC. Estes resultados sugerem que o momento da aplicação pode ser um fator determinante para observação dos resultados. De acordo com Ribeiro et al, a dose de $1 \mathrm{~J} / \mathrm{cm}^{2}$ aplicada em momentos específicos do processo cicatricial acelera a cicatrização de queimaduras cutâneas in vivo ${ }^{29}$. 
O resultado da análise fluxométrica mostrou aumento de fluxo sangüíneo no dia 8 e 10 com posterior queda ao longo do período de análise. Os grupos irradiados apresentaram diferença estatística significante em relação ao controle no dia 21.

No dia 3 do experimento, os animais do grupo irradiado com $4 \mathrm{~J} / \mathrm{cm}^{2} \mathrm{em}$ dose única no dia 1, apresentaram, em análise descritiva, aumento de fluxo em relação ao grupo dose fracionada e o grupo controle não irradiado, que teve seu fluxo levemente diminuído neste dia, porém, sem diferenças estatísticas significantes entre os grupos.

O fluxo aumentou significantemente $(p<0.05)$ no dia 8 em relação ao dia 3 para os três grupos estudados. Com o decorrer do tempo, retornou aos níveis iniciais, concordando com os resultados obtidos por Núnez e colaboradores ${ }^{8}$. No trabalho de Núñez et al, obteve-se um acentuado aumento de fluxo no dia 7 seguido de queda no dia 14, retornando a um patamar mais próximo ao valor inicial no dia 21 . O aumento de fluxo sangüíneo no dia 8 pode ter sido ocasionado pelo aumento de fluxo observado no tecido de granulação característico desta fase reparatória ${ }^{37}$.

Os grupos irradiados e controle têm seus fluxos menores no dia 10 quando comparados ao dia 8, não apresentando diferenças estatísticas entre estes momentos. No $15^{\circ}$ dia do experimento, os grupos irradiados e controle ainda apresentavam seus fluxos menores, porém, o grupo dose fracionada, em análise descritiva, apresentou uma queda mais acentuada quando comparado ao grupo dose única e controle e quando comparada ao dia 8 e 10 .

Aos 21 dias pós-criação da ferida, os grupos irradiados e controle não irradiado 
apresentaram o fluxo ainda inferior o que está de acordo com o comportamento esperado.

Quando confrontamos os resultados da análise de quantificação de vasos neoformados com a análise do monitoramento de fluxo sangüíneo no dia 21 do experimento, podemos observar que ò GC apresentou maior quantidade de vasos quando comparado aos grupos irradiados, porém menor fluxo sangüíneo. Este resultado pode ser esperado considerando que a quantidade de vasos sangüíneos em determinada região não está diretamente relacionada com o fluxo sangüíneo local, uma vez que o plexo capilar pode apresentar maior, menor ou nenhum fluxo sangüíneo dependendo de fatores locais ${ }^{13}$.

O sistema circulatório pode ser comparado a uma rede de tubos contendo líquido. Sendo fluxo, a vazão, ou o volume de líquido que passa por uma seção qualquer do tubo por unidade de tempo. As diferenças de pressão entre as extremidades do tubo, seu raio e comprimento e a viscosidade do líquido são variáveis que controlam o fluxo.

Na microcirculação sangüínea, o fluxo sangüíneo é controlado também pelas arteríolas, que são os últimos vasos pré-capilares responsáveis por reduzir a pressão arterial que atingirá os capilares através das variações do seu calibre. As variações de calibre podem ser da ordem de 1 para 4, variando o fluxo nestes vasos entre 260 vezes até 625 vezes na irrigação muscular. O fluxo sanguíneo é também controlado pelos capilares, que são vasos delgados constituídos por uma única camada de célula, de pequeno comprimento e numerosos. O fluxo sangüíneo nos capilares é regulado por um anel, o esfíncter précapilar, permitindo a abertura e fechamento do plexo em sua porção $\operatorname{arteriolar}^{13}$.

De acordo com Blot et al, na avaliação de trabalhos onde é demonstrada a 
reparação tecidual de feridas cutâneas, a maior dificuldade é estabelecer um critério para verificação da eficácia dos métodos utilizados. Segundo os autores, o uso do monitoramento de fluxo através da fluxometria Laser Doppler é um bom método de avaliação, pois fluxos elevados indicam um prognóstico bom para a reparação tecidual, enquanto que um fluxo diminuído pode indicar dificuldades ou impossibilidade de reparação espontânea ${ }^{30}$. O uso da fluxometria laser Doppler está bem estabelecido para a monitoração da microcirculação sanguínea da pele na literatura especializada, porém tem sido constantemente demonstrado que há uma variação espacial substancial nos valores de perfusão do tecido, mesmo em áreas adjacentes, levando a dificuldades experimentais ${ }^{38}$.

Este estudo experimental demonstra a possibilidade da utilização da irradiação com laser de baixa potência para aceleração de reparação de queimaduras cutâneas de acordo com o modelo proposto. Contudo, mais estudos devem ser realizados com diferentes parâmetros e momentos de irradiação, para elucidar as funções da radiação laser em cicatrização de queimaduras severas de pele, bem como avaliar as alterações de fluxo sangüineo decorrentes desta terapia. 


\section{CONCLUSÃO}

- De acordo com a análise histomorfométrica semi-quantitativa, os resultados deste estudo indicam que a terapia com laser em baixa intensidade acelera o processo de cicatrização de queimaduras de $3^{\circ}$ grau criadas na pele dos ratos estudados comparando a um controle não-irradiado. Na análise da fluxometria laser Doppler, não foram observadas evidências suficientes para afirmar que a microcirculação sangüínea apresentou diferenças significativas entre os grupos estudados.

- Comparando dose única e dose fracionada, nos parâmetros de irradiação proposto neste estudo, não foram observadas evidências suficientes de que ocorreu aceleração do processo cicatricial dependente da dose utilizada. 


\section{Referências Bibliográficas}

1- MONSTREY, S.; HOEKSEMA, H.; SAELENS, H.; DEPUYDT, K.; HAMDI, M.; VAN LANDUYT, K.; BLONDEEL, P. A conservative approach for dermal burn wounds using polarized-light therapy. Brit. J. Plast. Surg., v.55, p.420-6, 2005.

2- ATIYEH, B. S.; GUNN, S. W.; HAYEK, S. N. State of the art in burn treatment. World J. Surg., v.29, p.131-48, 2005.

3- MESTER, E. A laser sugar alkamazaea a gyogyaezatban. Orv. Hetilap. v.107, p.1012, 1966 apud ALMEIDA-LOPES, L. Análise in vitro da proliferação celular de fibroblastos de gengiva humana tratados com laser de baixa potência. Dissertação de Mestrado, Universidade Vale do Paraíba, São Paulo, 1999.

4- SCHINDL, A.; SCHINDL, M.; SCHÖN, H. P.; SCHINDL, L. Low-intensity laser therapy. A review. J.Invest. Med., v. 48, p. 312-26, 2000.

5- REDDY, GK. Photobiological basis and clinical role of low-intensity lasers in biology and medicine. J. Clin. Laser Med. Surg., v. 22, p. 141-50, 2004.

6- TÚNER, J.; HODE, L. It's all in parameters: a critical analysis of some well-know negative studies on low-level laser therapy. J. Clin. Laser Med. Surg., v.16, p. 245-8, 1998.

7- DANHOF, G. Biological effects of the laser beam. In: SIMUNOVIC, Z. Lasers in Medicine and Dentistry: Basic Science and Up-to-Date Clinical Application of LowEnergy Level Laser Therapy- LLLT, Rijeka-Croácia, Vitagraf, 2000. P.127-52.

8- NÚN๋EZ, S.C.; NOGUEIRA, G. E. C.; RIBEIRO, M. S.; GARCEZ, A. S.; LAGEMARQUES, J. L. He-Ne laser effects on blood microcirculation during wound healing: a method of in vivo study through laser Doppler flowmetry. Lasers Surg. Med., v. 35, p. 363-8, 2004. 
9- HALL, G.; ANNEROTH, G.; SCHENNINGS, T.; ZETTERQVIST, L.; RYDÉN, H. Effect of low level energy laser irradiation on wound healing. An experimental study in rats. Swed. Dent. J., v. 18, p. 29-34, 1994.

10- SCHLAGER, A.; KRONBERGER, P.; PETSCHKE, F.; ULMER, H. Low-power laser light in the healing of burns: a comparison between two different wavelengths $(635 \mathrm{~nm}$ and $690 \mathrm{~nm}$ ) and a placebo group. Lasers Surg. Med., v.27, p.39-42, 2000.

11- JUNQUEIRA, L.C; CARNEIRO,J. Histologia Básica. Guanabara Koogan, Rio de Janeiro, Brasil, 1995.

12- PEREIRA, F.E.L. Degenerações. Morte Celular. Alterações do Interstício. Em: BOGLIOLO-Patologia Geral, Guanabara Koogan, Rio de Janeiro, Brasil, p.38-68, 1998.

13- ROBBINS, S.L.; COTRAN, R.S.; KUMAR, V. Robbins phatologic basis of diseases. 6. ed. Philadelphia:W.B. Saunders, 2000.

14- Clínicos e Ocupacionais. Rev. Bras. Saúde Ocupacional. v.25, p.77-100, 1999.

15- FONTANA, C. Fisiologia da cicatrização das feridas. Cicatrização, v.1, n.1, p.3-22, 1996.

16- BAYAT, M.; VASHEGHANI, M. M.; RAZAVI, N.; TAHERI, S.; RAKHSHAN, M. Effect of low-level helium-neon laser therapy on the healing of thirdy-degree burns in rats.

J. Photochem. Photobiol. B: Biol., v.83, p.87-93, 2006.

17- DESANTI, L. Pathophysiology and current management of burn injury. ADV Skin wound care. v.18, p.323-332, 2005.

18- BISHARA, S. A.; SHADY, N. H.;GUNN, S. W. New technology for burn wound closure and healing. A review. Burns. V.31, p.944-956, 2005.

19- FERGUSON, M.W.J.; LEIGH, I.M. Clinical aspect of wound healing. Wound healing. 2005 . 
20- ÜLKÜR, E.; ONCUL, O.; KARAGOZ, H.; YENIZ, E.; ÇELIKÖZ, B. Comparison of silver-coated dressing (ActicoatTM ), chlorexidine acetate $0.5 \%$ ( BactigrassR ), and fusidic acid $2 \%$ (FucidinR ) for topical antibacterial effect in methicillin-resistent Staphylococci-contaminated, full-skin thickness rat burn wounds. Burns. 2005.

21- VINCENT, K. M. P.; BURD, A. In vitro cytotoxity of silver: implication for clinical wound care. Burns. v.30, p.140-147, 2004.

22- MISERENDINO, L.J.; PICK, R.M. Laser in dentistry. Chicago. Quintessence, p.247, 1995.

23- MESTER, E. et al. The stimulationg effect of low power laser rays on biologicL systems. Laser Rev., v.1, p.3, 1968.

24- MESTER, E. et al. Effect of laser rays on wound healing. Am. J. Surg. v.122, p.532$535,1971$.

25- HAINA, D. et al. Animal experiments in light induced wound healing. Laser Basic Biom. Res., v.22, p.1, 1981.

26 BISHT, D.; GUPTA, S.C., MISRA, V.; MITAL, V.P. \& SHARMA, P. Effect of low intensity laser radiation on healing of open skin wounds in rats. Indian J. Med. Res. v100, p.43-46, 1994.

27- CAMBIER, D.C.; VANDERSTRAETEN, G.G.; MUSSEN, M.J.; VAN DER SPANK, J.T. Low power laser and healing of burns. A preliminary assay. Plast. Reconstr. Surg., v.97, p.555-8, 1996.

28- SCHLAGER, A.; KRONBERGER, P.; PETSCHKE, F.; ULMER, H. Low-power laser light in the healing of burns: a comparison between two different wavelengths $(635 \mathrm{~nm}$ and $690 \mathrm{~nm}$ ) and a placebo group. Lasers Surg. Med., v.27, p.39-42, 2000. 
29- RIBEIRO, M.S.; SILVA, D.F.T.; ARAÚJO, C.E.N.; OLIVEIRA, S.F.; PELEGRINI, C.M.R.; ZORN, T.M.T.; ZEZELL, D.M. Effects of low-intesity polarized visible laser radiation on skin burns: a light microscopy study. J. Clin. Laser Med. and Surg. v.22, p.59-66, 2004.

30- BLOT, S. I., MONSTREY, S. J.; The use of laser Doppler imaging in measuring wound healing progress. Arch Surg. v.136, p.116, 2001.

31- PETERSEN, S.L. et al. The effect of LLLT on wound healing in horses. Equine Vet. J. v.31, p.228-231, 1999.

32- SHAKESPEARE, P. G. The role of skin substitutes in the treatment of burn injuries. Clinics in Dermatology. v.23, p.413-418, 2005.

33- LEE, A. R. C.; LEEM, H.; PARK, K.C. Reversal of silver sulfadiazine-impaired wound healing by epidermal growth factor. Biomaterials. v.26, p.4670-4676, 2005.

34 -JOSEPH, J.N.; KENDALL, R.R.; STEVEN, E.W.; DAVID, N.H. The use homograft compared to topical antimicrobial therapy in the treatment of second degree burns of more than $40 \%$ total body surface area. Burns. v.30, p.548-551, 2004

35 -ARAÚJO, C.E.; RIBEIRO, M.S.; FAVARO, R.; ZEZELL, D.M.; ZORN, T.M.

Ultrastuctural and autoradiographical analysis show a faster skin repair in He-Ne lasertreated wounds. J. Photochem. Photobiol. 2006.

36- STADLER, I.; LANZAFAME, R.J.; EVANS, R.; NARAYAN, V.; DAILEY, B.; BUEHNER, N.; NAIM, J.O. $880 \mathrm{~nm}$ irradiation increases the wound tensile strength in a diabetic murine model. Lasers in Surgery and Medicine. v.28, p.220-226, 2001. 39- CONLAN, M.J.; RAPLEY, J.W.; COBB, C.M. Biostimulation of wound healing by low-energy laser irradiation: a review. J. Clin. Periodontol., v.23, n.5, p.492-496, 1996. 
38 - OBAID, S.; MORRIS, D. J. Laser Doppler perfusion imager use in incisional hernia repair following omental breast reconstruction. Plast. Reconst. Surg. v.6, p.109, 2002. 